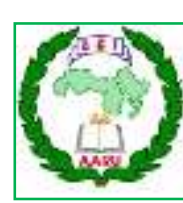

13

مجلة اتحاد الجامعات العربية للعلوم الزراعية، جامعة عين شمس، القاهرة، مصر

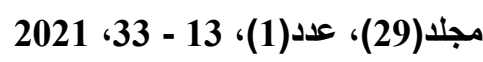

Website: http://ajs.journals.ekb.eg

DOI: 10.21608/ajs.2021.51709.1306

دور نظم الجودة فى تنمية الصادرات الزراعية المصرية

[2]

\author{
مها محمد السيد النمكى* - سلوى محمد أحمد عبد المنعم - حسين السيد سرحان

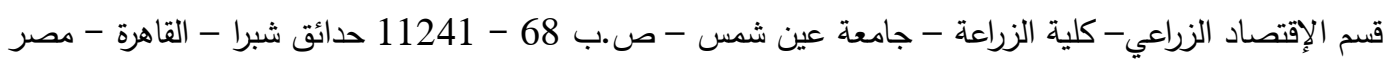

*Corresponding author: melnamky27@gmail.com

Received 30 November, 2020

Accepted 8 February, 2021

التي يتم توفيرها. وفيما يتعلق بدراسة اثر تطبيق معايير

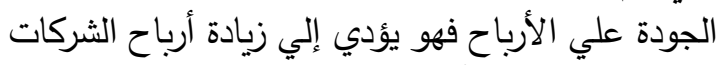
بنسبة 25\%، كما أنه يؤدي الي زيادة الحصة السودي السوقية

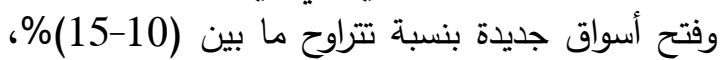
كما أشارت النتائج التي تم التوصل إليها الي أن تطبيق

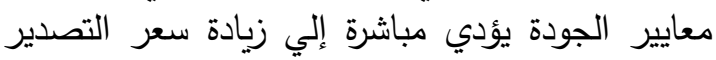

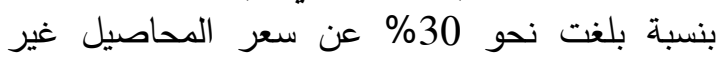
المطبق عليها معايير الجودة. وقد اشارت نتائج البحث

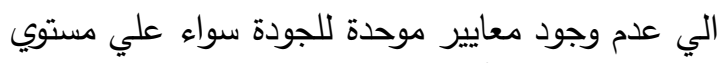

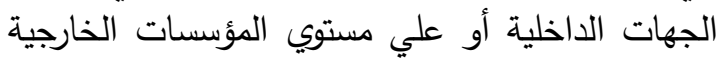

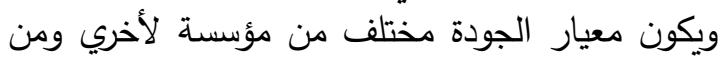

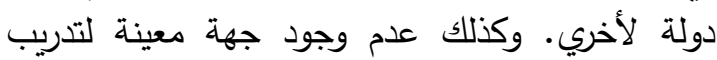
العاملين علي مواصفات الجودة بالإضافة لعدم وجئ وجود

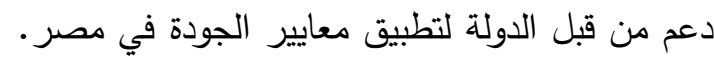
فيما يتعلق بالأثر الفعلى لتطبيق الجودة توصلئ النيق النتائج

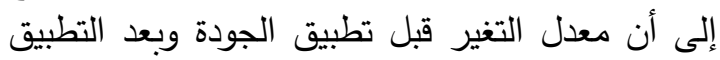

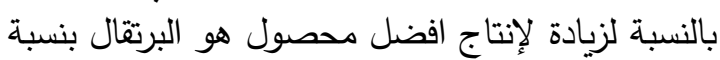

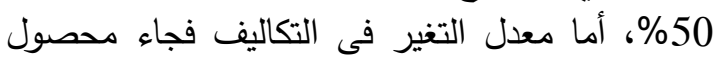

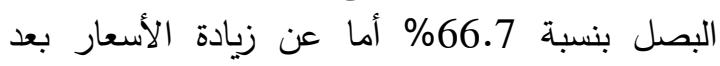

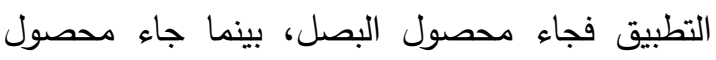

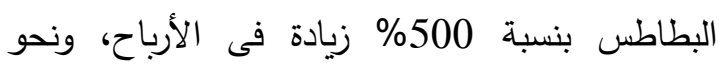
355 بالنسبة لعائد الجنيه على الطن.

الكلمات المفتاحية: مفهوم الجودة، التفوق، معايير

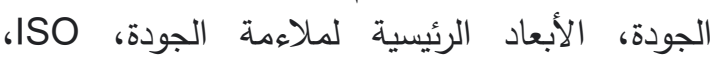

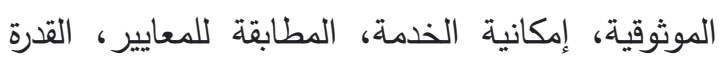

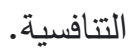

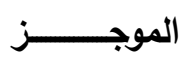

تعد جودة الصادرات الزراعية من أهم الأسس التي تقوم عليها تتمية وتحسين هذه الصادرات للأسواق الصناق

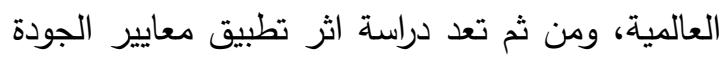

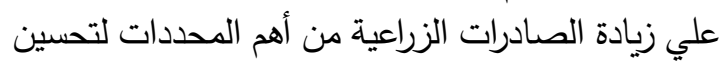
منظومة تلك الصادرات. وبدراسة الأهمية النسبية للمحاصيل الزراعية بعينة البحث والتي تتمثل في كل من التصني

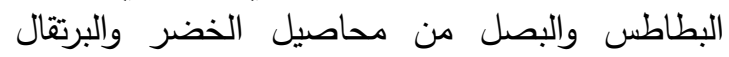
والعنب من محاصيل الفاكهة تبين ان صادرات البطاطس والبرن والبصل تمثل نحو 25\%، 21\% من العمالي صادرات الخضر كمتوسط للفترة (2014-2018)، بينما بلغت صادرات البرتقال نحو 528 مليون دولار تمثل نحو 2014) بينا بلغت 53 من صادرات الفاكهة والتي بلغت حوالي 983 مليون دولار كمتوسط للفترة المشار اليها في حين بلغت ولت الفت حولت

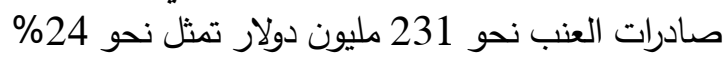

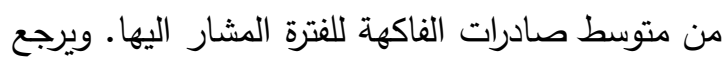

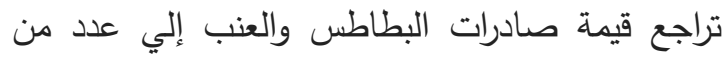

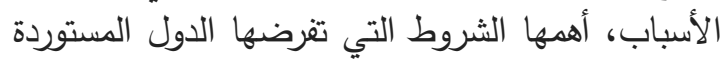

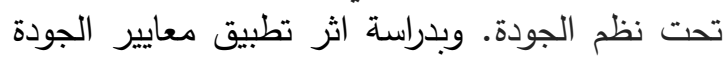

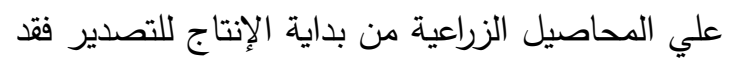

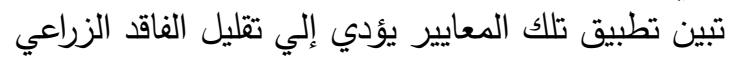

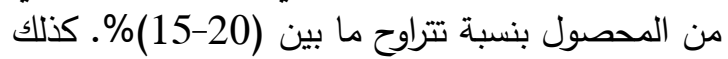
فإن تطبيق معايير الجودة يؤدي إلي زيادة تكاليف إنتاج

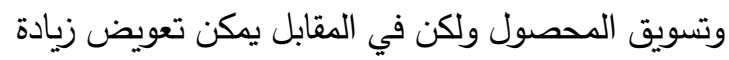

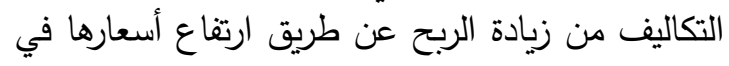

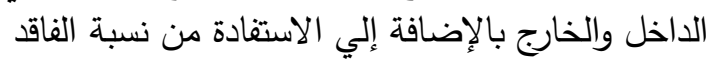




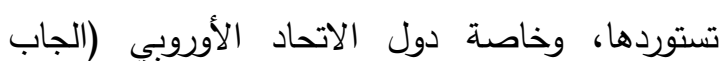

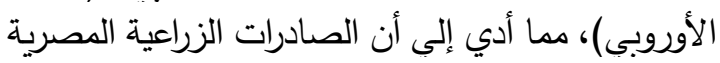

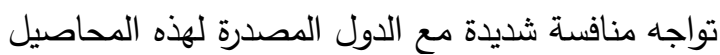
والتى لا تتطابق مع المواصفات المطلوبة لافية من قبل الدول الدول المستوردة، وعدم الاهتمام بالحصول على شلى شهادات

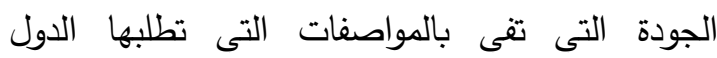

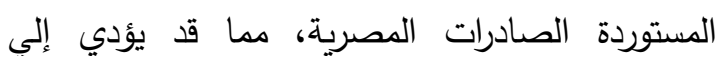
انخفاض كمية وقيمة بعض الصادرات الزراعية المصرية

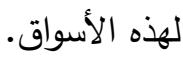

\section{3 هدف البحث}

يستهدف البحث التعرف علي أهم نظم الجودة المطبقة على القطاع الزراعى المصري بداية من وضع النع البذرة للححصول ومصادر الحصول عليها حتى نهاية العاية مرحلة الإنتاج ومعاملات مابعد الحصاد. قياس أثر تطبيق نظم الجودة علي أهم المحاصيل

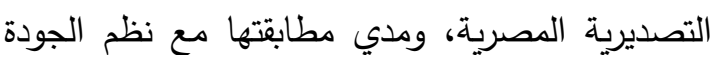

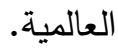

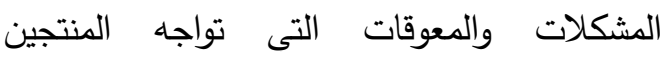

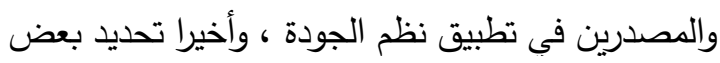

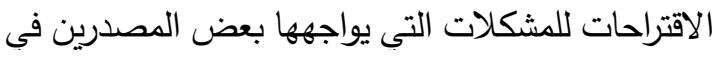
تطبيق نظم الجودة على الصادرات الزراعية المصرية.

\section{4 الطربقة البحثية ومصادر البيانات}

استخدم البحث كلاً من أسلوبي التحليل الوصفي الأبي

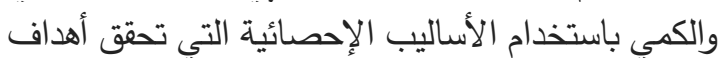

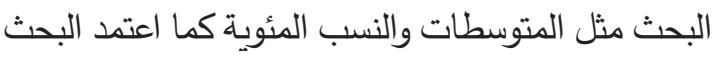

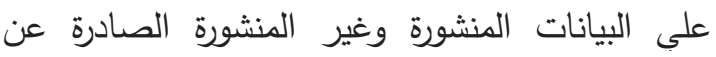
الجهات ذات العلاقة بموضوع البحث مثل الجهاز المركزي للتعبئة العامة والإحصاء، وقاعدة بيات العانات العات مركز

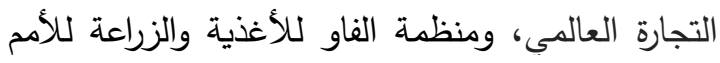

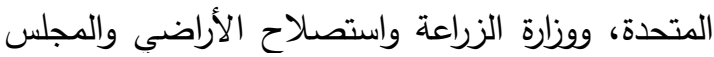

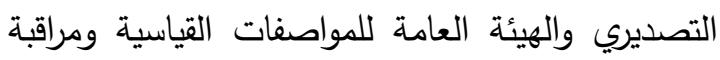

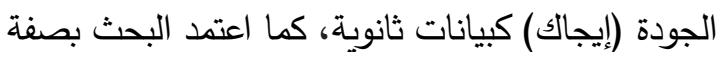

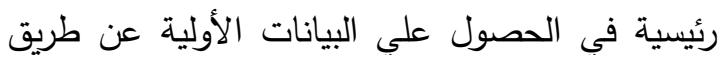

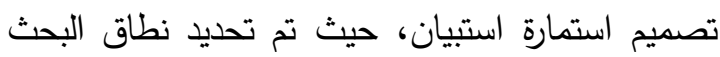
ليشمل الثركات التي تقوم بتصدير الدحاصيل الزراعية،

\section{1}

نظراً لأهمية تأثير تطبيق نظم الجودة علي تتمية

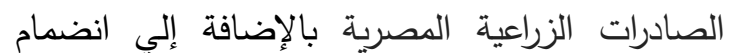
مصر إلى العديد من التكتلات الاقتصادية الإقليمية

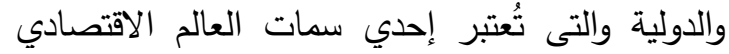

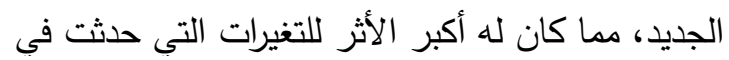

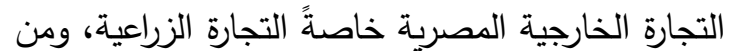

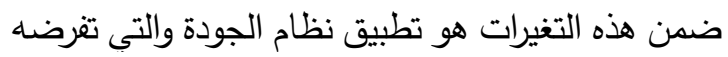

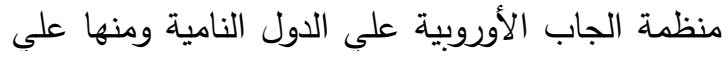
صادرات مصر الزراعية وهى تطبيق مواصفات معينة لإدية

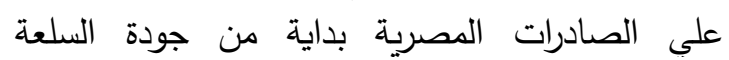
والمؤسسات المنتجة لهذه السلعة والمواصفات والمعايير البيئية تُطبق على السلعة بداية من زراعتها حتى إنتاجها،

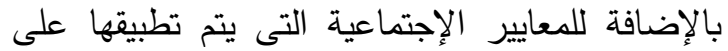

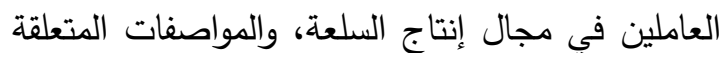

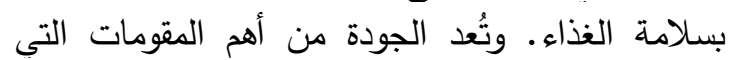

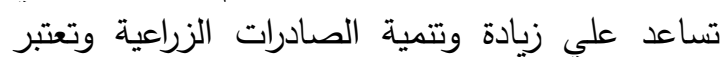
قضية تتمية الصادرات الزراعية من أهم التحديات التي التي

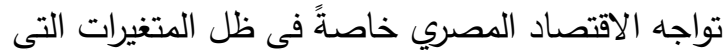
تؤثر علي القطاع الزراعي المصري بأكمله، الأمر الذي الذي التي

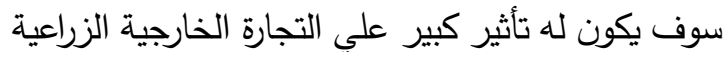

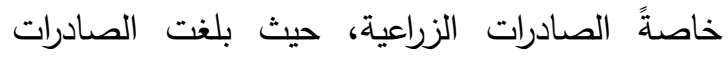

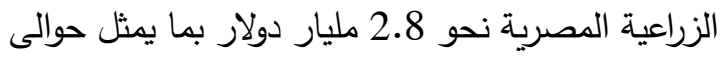

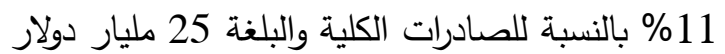
خلال الفترة (2014-2018)، كما بلغ متوسط صادرات الخضر والفاكهة حوالى 872،

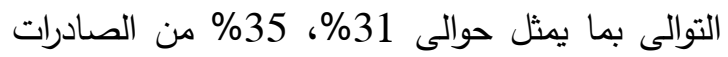
الزراعية المصرية خلال نفس الفترة.

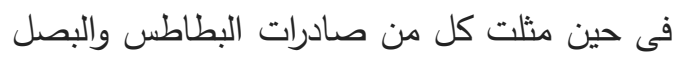
نحو 25\%، 21\% من إجمالي صادرات الخضر والبالغة خلال الفترة (2014-2018)، بينما مثلت صناد صادرات البرتقال والعنب حوالي 53\%، 24\% من صادرات

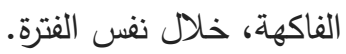

\section{2 مشكلة البحث}

تتمثل مشكلة البحث في أن الدول المستوردة حددت

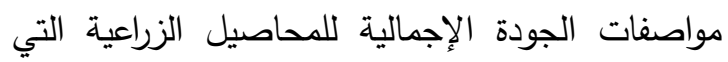


كما يتضح أن متوسط القيمة الإجمالية لصادرات الخضر والفاكهة بلغت حوالي 872، التوالي، حيث اتضح أن متوسط صادرات الخضر تمثل

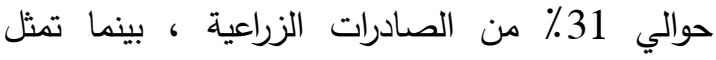

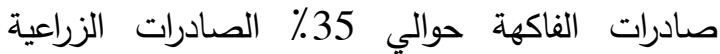
كمتوسط للفترة المشار إليها.

2- الأهمية النسبية للمحاصيل الزراعية في عينة البحث من إجمالي صادرات الخضر والفاكهة تُشير بيانات "الجدول رقم 2 إلي الأهمية النسبية

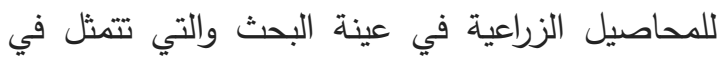

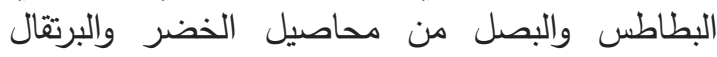
والعنب من محاصيل الفاكهة. شكلت كل من صنادي صادرات

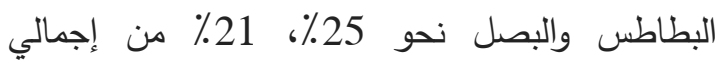
صادرات الخضر والبالغة نحو 872 كمتوسط مليون

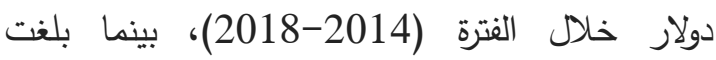
صادرات البرتقال حوالي 528 مليون دولار ، تمثل نحو

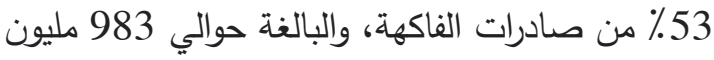
دولار كمتوسط خلال الفترة المشار إليها، بينما بلغت الئالي

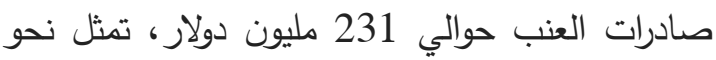

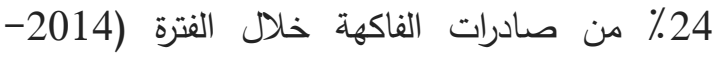

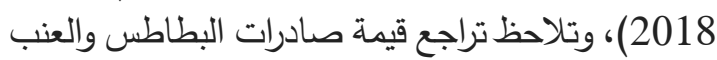

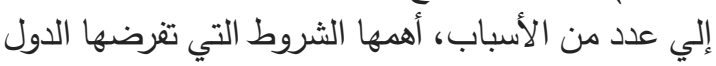
المستوردة تحت نظم الجودة.

ثانياً: الأهمية النسبية للشركات الحاصلة علي نظام

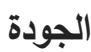
تتاول البحث عدداً من الثركات المعنية بالصادرات

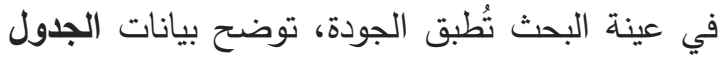

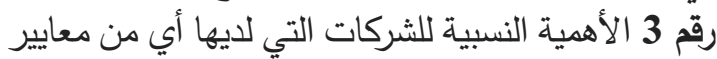

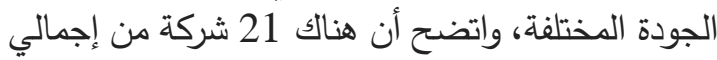

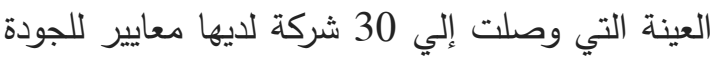

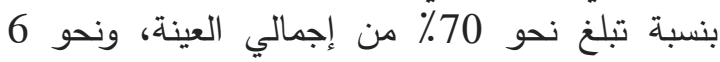

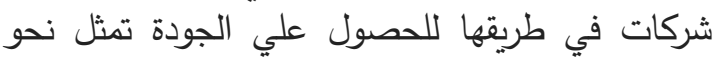

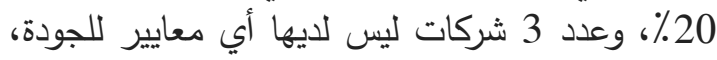

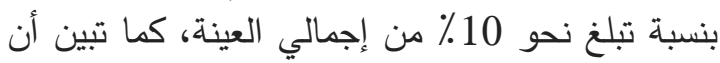

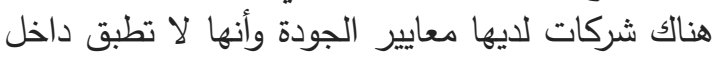

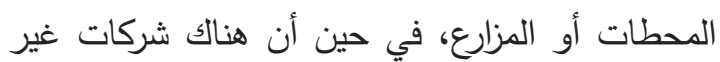

والتي يتم التصدير بها عن طريق المحطات التصديرية،

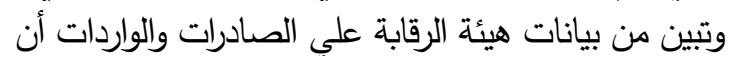
عدد المحطات التصديرية بلغ نحو 98 محطة تصديرية التئة

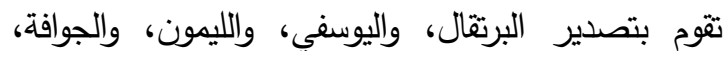

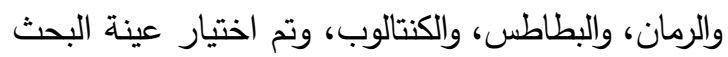

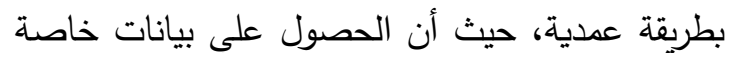

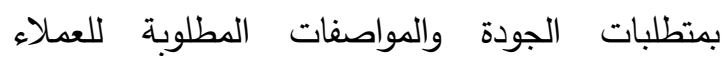
الخارجيين يعتبره كثير من المصدرين من الأمور السرية،

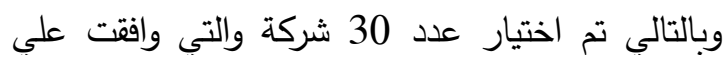

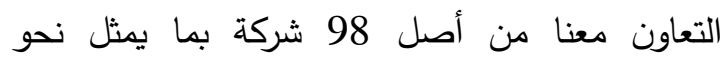
30.6\% الكثير منها تطبق نظم الجودة، وقد تم اعداد استمارة الاستقصاء لأخذ رأي المصدئ تلفرين في دور الجودة

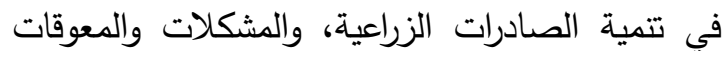

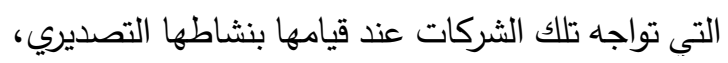
وآراء المصدرين في التغلب علي تلك المشكلات.

\section{5 مناقشة النتائج}

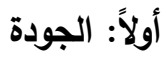

\section{- مفهوم الجودة Quality -} تُعرف الجودة بأنها درجة وفاء المنتج لاحتياجات

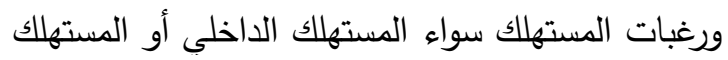

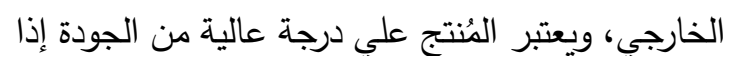
كان تصميمه وتعبئته وتغليفه ودرجة إنتاجه أو الاستخدام

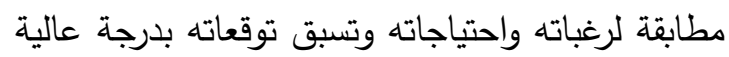

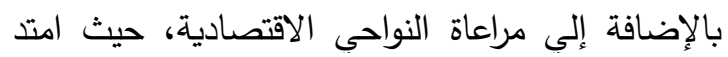

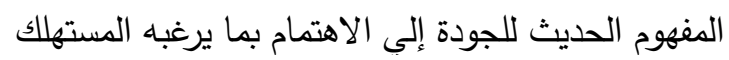

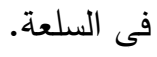

ثانياً: الوضع الراهن للصادرات الزراعية المصرية 1- الأهمية النسبية للصادرات الزراعية من إجمالي الصادرات المصرية يتضح من بيانات الجدول رقم 1 أن متوسط الندات

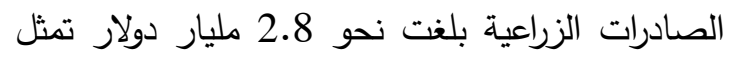
حوالي 11\% من إجمالي الصادرات الكلية والبالغة حوالي لئل 25 مليار دولار كمتوسط للفترة (2014-2018). 
جدول 1. الأهمية النسبية لإجمالى الصادرات الزراعية والخضر والفاكهة من إجمالى الصادرات المصرية خلال الفترة (القيمة بالمليون دولار )

\begin{tabular}{|c|c|c|c|c|c|c|c|}
\hline$\%$ & صادرات الفاكهة & $\%$ & صادرات الخضر & $\%$ & الزراعية & الكلية الصادرات & السنة \\
\hline 32 & 945 & 23 & 674 & 11 & 2955 & 27542 & 2014 \\
\hline 31 & 884 & 27 & 762 & 13 & 2853 & 21340 & 2015 \\
\hline 34 & 930 & 34 & 913 & 12 & 2696 & 22580 & 2016 \\
\hline 37 & 1028 & 39 & 1083 & 11 & 2801 & 26397 & 2017 \\
\hline 40 & 1127 & 33 & 930 & 10 & 2791 & 29215 & 2018 \\
\hline 35 & 983 & 31 & 872 & 11 & 2819 & 25415 & المتوسط \\
\hline
\end{tabular}

• متوسط هندسي للنسب المئوية.

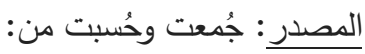

1) وزارة الزراعة واستصلاح الأراضي، قطاع الثئون الاقتصادية، (نشرة التجارة الخارجية)، أعداد مختلفة. 2) الجهاز المركزي للتعبئة العامة والإحصاء، الإعب، وركز المعلومات)،بيانات غير منشورة.

جدول 2. الأهمية النسبية للمحاصيل الزراعية من إجمالي الخضر والفاكهة خلال الفترة (2014-2018) (القيمة بالمليون دولار)

\begin{tabular}{|c|c|c|c|c|c|c|c|c|c|c|}
\hline \multicolumn{5}{|c|}{ صادرات الفاكهة } & \multicolumn{5}{|c|}{ صادرات الخضر } & \multirow{2}{*}{ |لبنة } \\
\hline$\%$ & صادرات & $\%$ & صادرات البرتقال & صادرات & $\%$ & صادرات البصل & $\%$ & صادرات & صادرات & \\
\hline 26 & 242 & 50 & 472 & 945 & 25 & 168 & 39 & 266 & 674 & 2014 \\
\hline 27 & 241 & 52 & 464 & 884 & 35 & 263 & 29 & 224 & 762 & 2015 \\
\hline 23 & 215 & 53 & 495 & 930 & 22 & 197 & 16 & 142 & 913 & 2016 \\
\hline 23 & 237 & 53 & 547 & 1028 & 19 & 207 & 24 & 263 & 1083 & 2017 \\
\hline 20 & 220 & 59 & 662 & 1127 & 13 & 117 & 21 & 196 & 930 & 2018 \\
\hline 24 & 231 & 53 & 528 & 983 & 21 & 190 & 25 & 218 & 872 & المتوسط \\
\hline
\end{tabular}

• متوسط هندسى للنسب المئوية.

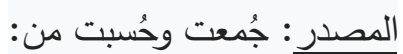

1) وزارة الزراعة واستصلاح الأراضي، قطاع الثئون الاقتصادية، (نشرة التجارة الخارجية)، أعداد مختلفة.

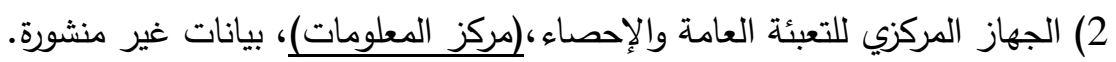


شركات من عينة البحث حاصلة على شهادة الجودة

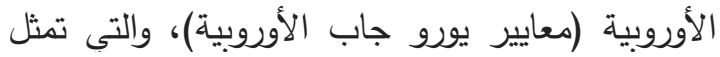

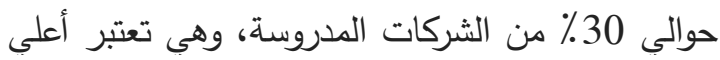

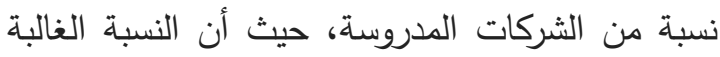

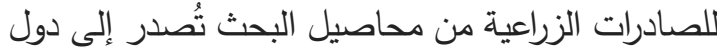

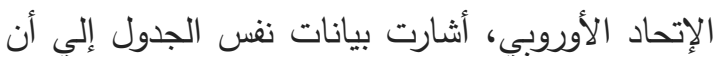

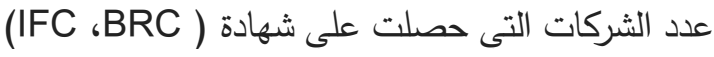

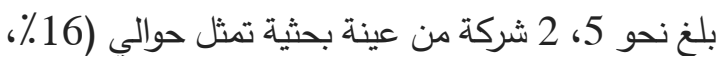
7\%) من الشركات في عينة البحث علي التوالي، عند بينما

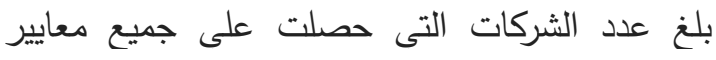

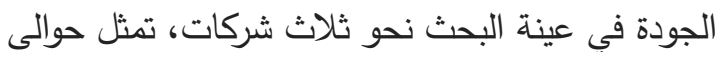

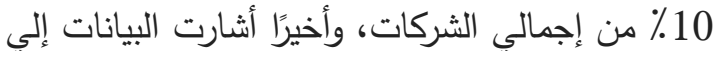

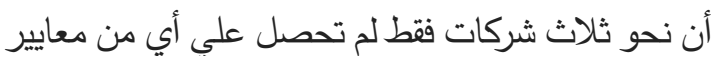
الجودة ، والتي تمثل حوالى 10٪ من عينة البحث. جدول 4. أهم معايير الجودة المطبقة علي الشركات في

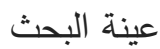

\begin{tabular}{|c|c|c|}
\hline النسبية\% & عدد الشركات & الجم معايير المطدة \\
\hline 27 & 8 & $\begin{array}{c}\text { إدارة الجودة } \\
\text { (ISO) }\end{array}$ \\
\hline 30 & 9 & $\begin{array}{c}\text { الأوربية } \\
\text { Euro Gap } \\
\text { Euroيز }\end{array}$ \\
\hline 16 & 5 & شهادة BRC \\
\hline 7 & 2 & شهادة IFS \\
\hline 10 & 3 & كل ماورد \\
\hline 10 & 3 & لا لا تطبق \\
\hline 100 & 30 & الإجمالي \\
\hline
\end{tabular}

المصدر : جُمعت وحُسبت من استبيان البحث الميدانى في عام 2020.
حاصلة علي الجودة ويتم تطبيق الجودة فعلياً، إلا أن نظام الجودة يتطلب وجود دورة مستتدية متكاملة يتم الحفاظ عليها لكدة عامين على الأقل. جدول 3. الأهمية النسبية للشركات التي تحصل على معايير الجودة في عينة البحث

\begin{tabular}{|c|c|c|}
\hline \multicolumn{2}{|c|}{ الشركات الحاصلة علي نظام } & \multirow{2}{*}{ البند } \\
\hline \% من إجمالي & العدد & \\
\hline 70 & 21 & تُطبق نظام الجودة \\
\hline 20 & 6 & في الطريق لتطبيق \\
\hline 10 & 3 & لم يتم تطبيق الجودة \\
\hline 100 & 30 & الإجمالي \\
\hline
\end{tabular}

ثالثاً: أهم معايير الجودة والمؤسسات المسئولة عن تنفيذها في مصر المعر تتتاول الجزئية الثالثة من البحث محورين، أولهما

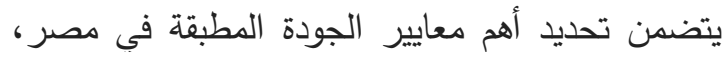

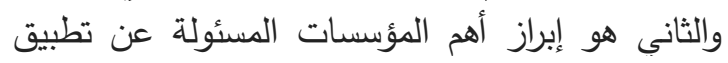

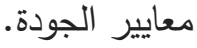

$$
\text { 1- أهم معايير الجودة المطبقة في مصر }
$$
تشير بيانات الجدول رقم 4 إلي أني أندوة أهم معايير الجودة المطبقة في مصر تقتصر علي حولئي اليى أربعة معايير للجودة، والتي تقتصر علي (إدارة الجودة الثاملة

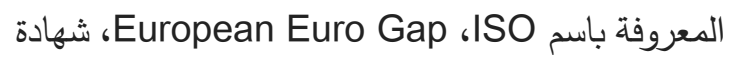
(BRC خلال تقائ الإندان IFS خلال نتائج الاستبيان اتضح أن نحو 8 شركات فقط من

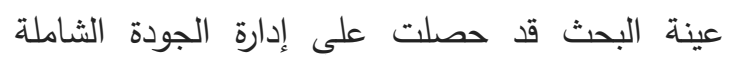

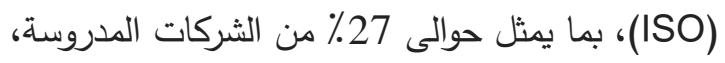
حيث أشارت البيانات من نفس الجدول إلى ألي أن نحو 9 
الفاصوليا، المانجو، العنب، الفلفل الأخضر، الفلفل الملون، والفراولة).

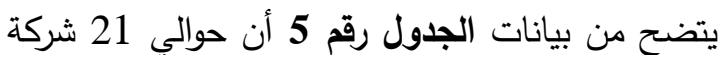
من أصل 30 شركة هي حجم العينة تقوم بإنتاج وتصدير

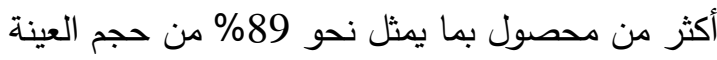

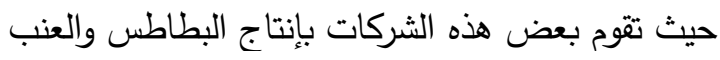

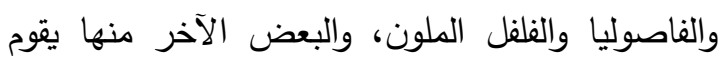
بإنتاج البرتقال، والبصل، والطماطح الثيري، والبعضي، والفراولة

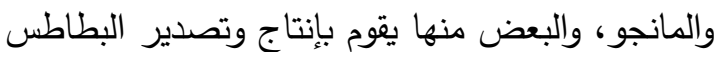

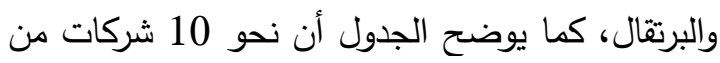

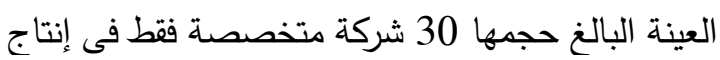

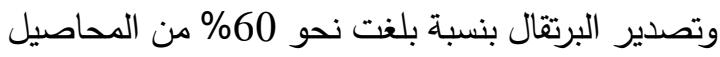
والباقي محاصيل أخري بما يمثل نحو 33\% بلغئ

جدول 5. أهم المحاصيل الزراعية المصدرة بشركات التصدير في عينة البحث

\begin{tabular}{|c|c|c|c|}
\hline نسبة التخصص & النسبية ألهمية & الشركات & المحصول \\
\hline 60 & 33 & 10 & البرتقال \\
\hline 50 & 27 & 8 & البطاطس \\
\hline 40 & 17 & 5 & الفراولة \\
\hline 40 & 13 & 4 & العنب \\
\hline 30 & 7 & 2 & المانجو \\
\hline 10 & 3 & 1 & غتير \\
\hline *\%34 & 100 & 30 & الإجمالي \\
\hline
\end{tabular}

$$
\text { "متوسط هندسي للنسب المئوية. }
$$

المصدر : جُمعت وحُسبت من استبيان البحث الميداني

$$
\text { في عام } 2020 .
$$

كما يتضح من بيانات نفس الجدول أن هناك نحو 8 ندات 8

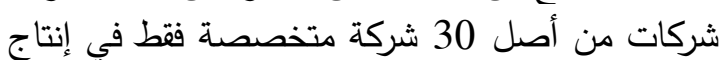
وتصدير البطاطس بنسبة 27\% من أصل أصل الشركات

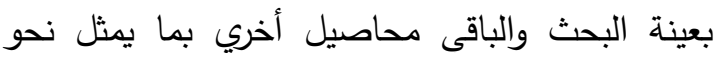
50 من حيث الأهمية النسبية للشركات التصديرية

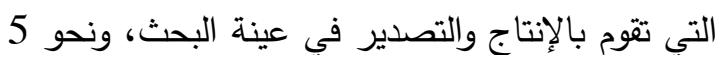

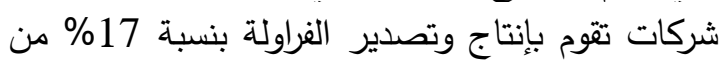

2- أهم المؤسسات المسئولة عن تطبيق معايير اتضح من خلاد الاستبيان أن المؤسسات التي تصدر وتراقب تطبيق معايير الجودة تتمثل في ما يلى الاني:

أ- المؤسسات الداخلية وأهمها

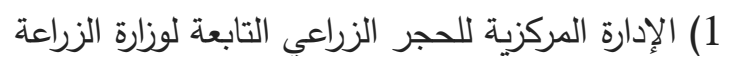

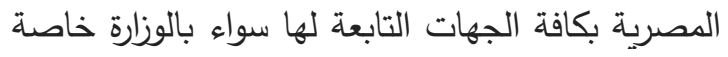

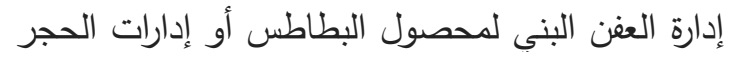
الزراعي بالمطارات والموانئ المصرية. 2) الهيئة العامة للرقابة على الصادراتئ والهات والواردات بوزارة التجارة والصناعة المصرية.

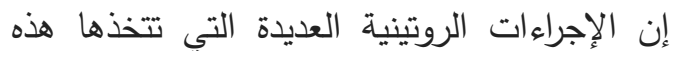

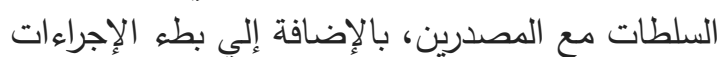

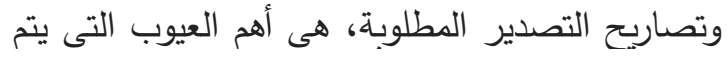

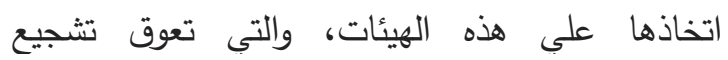
المصدرين علي زيادة حجم الصادرات المصرية إلي التئي

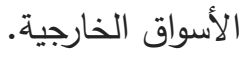

ب- المؤسسات الخارجية (الدولية): وهي مقسمة إلي مؤسسات حكومية وخاصة ومن هذه المؤسسات: إدارة الجودة الثاملة ISO وخاصة

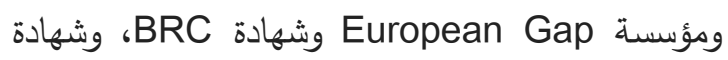
IIFS

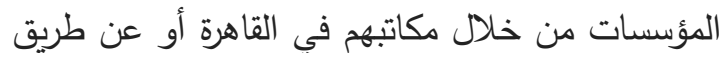
إرسال مندوبين من الخارج بالتعاون مع السلطات الداخد الداتية

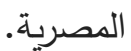
رابعاً: الهم المحاصيل الزراعية لثركات التصدير بعينة البحث

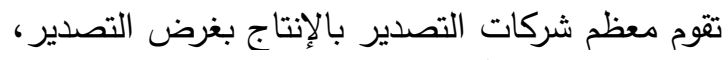

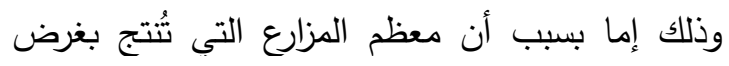

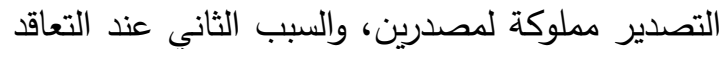

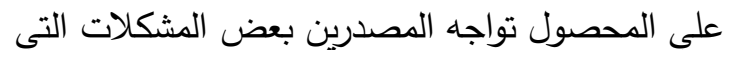
تعوق تطبيق نظم الجودة، مثال تطبيق نظام الجلوبال

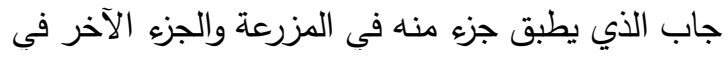

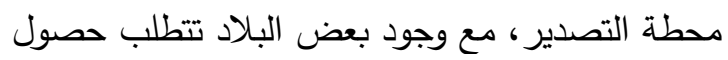

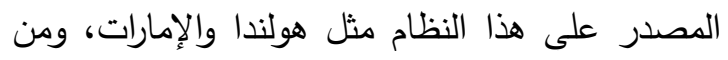
خلال عينة البحث يتضح أن معظم هذه الشركات تقوم

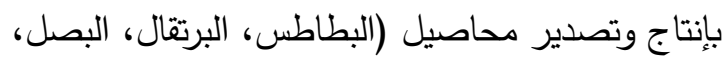


في عملية المراقبة علي عملية الإنتاج حيث تقوم الدول

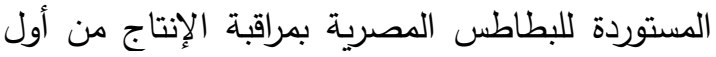

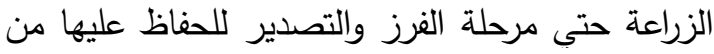
مرض العفن البنى، وحيث أن غالبية هذه الثركات تتعاقد على تصدير المحصول قبل الزبل الزراعة حسب إنب إتفاقية اليوروجاب وتشترط فيها الدول المستوردة أن يتم شراء

$$
\text { تقاوي البطاطس منها. }
$$

\section{3- 3 - 3 - 3صول الفراولة}

توضح بيانات الجدول رقم 6 أن عدد الثركات الذين

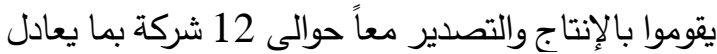
نحو 40\% من الشركات العاملة في مجال التصدير بعدير بالنسبة لمحصول الفراولة وتقوم بتصدير نحو 70 \%

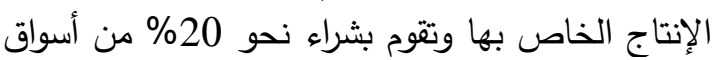
الجملة ونحو 10\% عن طريق الوسطاء أو عن طريق بريق مزارع أخري قريبة منها.

4- محصول المانجو حيث يتمتع محصول المانجو بميزة تنافسية عالية في الأسواق الخارجية لذا تكون نسبة الكمية المطلوب

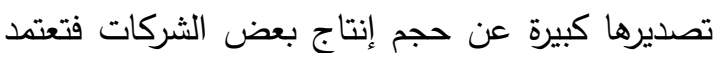

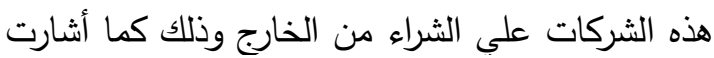
بيانات الجدول رقم 6 أن عدد الثركات الثات الذين الذين يقوموا

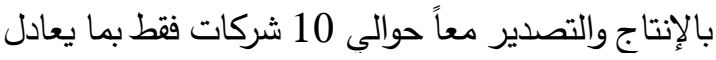
نحو 33\% من الشركات العاملة في مجال التصدير بالنسبة لمحصول المانجو تقوم بتصدير نحو 70 \%

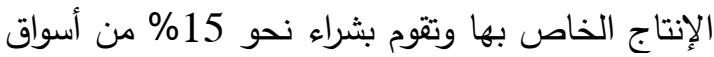

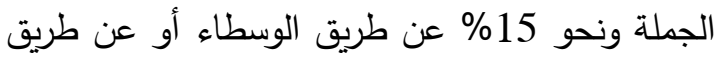
مزارع أخري قريبة منها.

سادساً: أهم الأسواق التي تصدر الثركات إليها بمقارنة أهم الأسواق التي يتم التصدير إليها في عينة

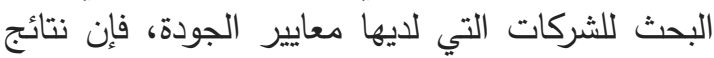
الجدول رقم 7 توضح ما يلي: أن أهم الأسواق يتم التحان

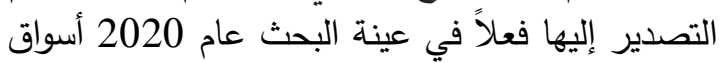

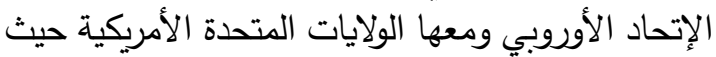

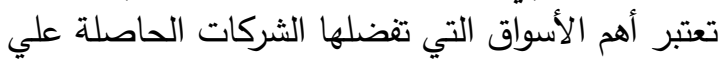
معايير الجودة للتصدير إليها حيث جاءت في المركير المركز الأول من حيث عدد الثركات التي بلغت 16 شركة بما لئ في التركا
أصل الثركات بعينة البحث والباقي محاصيل أخري بما

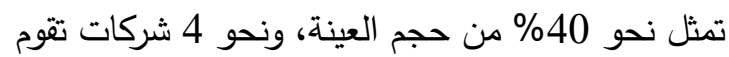

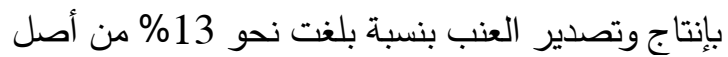
الثركات المبحوثة والباقي محاصيل أخري بما تمثل نحو

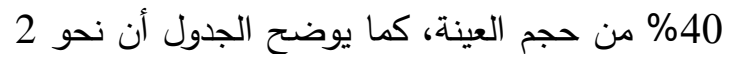

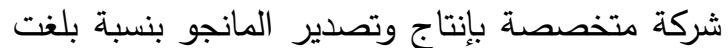
نحو 7\% من أصل الثركات بعينة البحث والباقي

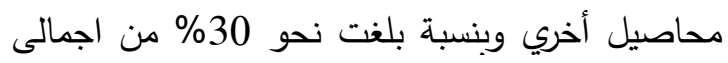
العينة، وشركة واحدة فقط غير متخصصة فئة في إنتاج

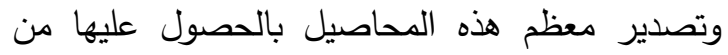

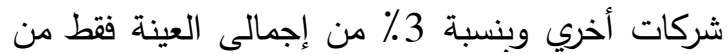
حيث الأهمية النسبية للشركات التصدية التصدية إنماتية التي تقوم بالإنتاج والتصدير في عينة البحث.

خامساً: مصادر شراء المحاصيل لشركات التصدير

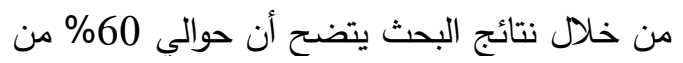
الثركات العاملة في مجال إنتاج وتصدير المحاصيل التهاليل

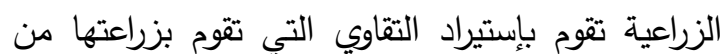

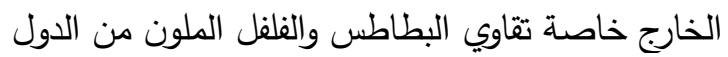

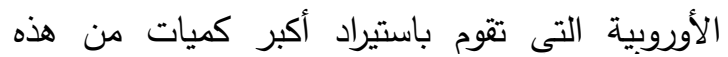

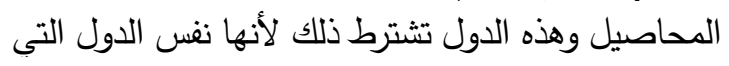

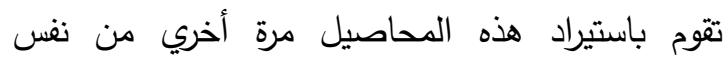
الشركات حسب إتفاقيات اليوروجاب.

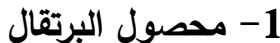

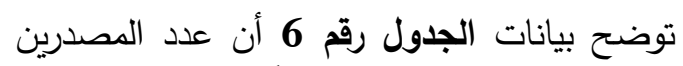

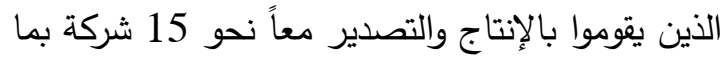
يعادل حوالى 50\% من الشركات العاملة في مجال التصدير بالنسبة لدحصول البرتقال التي تقوم بتصدير حوالى 80\% من الإنتاج الخاص بها وتقوم بشراء حوالى لئى لئل

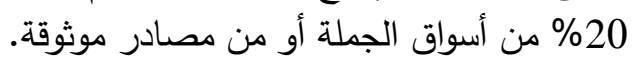

2- 2 - 2حصول البطاطس

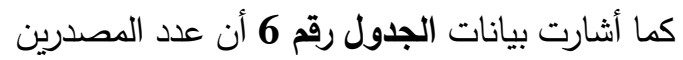

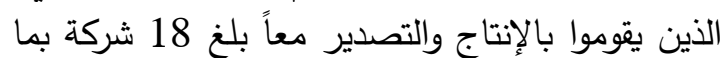

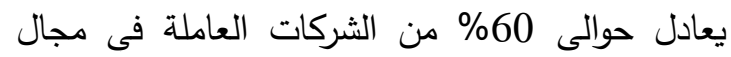
التصدير بالنسبة لمحصول البطاطس التي تقوم بتصدير

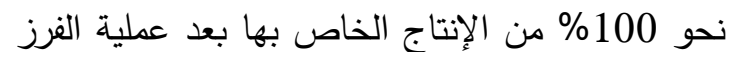
حيث تتميز البطاطس بمعايير جودة عالية جداً خاصة 
جدول 6. مصادر شراء أهم المحاصيل للشركات في عينة البحث

\begin{tabular}{|c|c|c|c|c|c|c|}
\hline \multirow{2}{*}{ الجملة\% } & \multirow{2}{*}{ أخري\% مصادر } & \multirow{2}{*}{ أسملةق\% } & \multirow{2}{*}{ الثركات\% مزارع } & \multicolumn{2}{|c|}{ الأهمية النسبية للشركات } & \multirow{2}{*}{ المحصول البيان } \\
\hline & & & & $* * \%$ & عدد الثركات & \\
\hline 100 & 0 & 20 & 80 & 50 & 15 & البرتقال \\
\hline 100 & 0 & 0 & 100 & 60 & 18 & البطاطس \\
\hline 10 & 10 & 20 & 70 & 40 & 12 & الفراولة \\
\hline 100 & 15 & 15 & 70 & 33 & 10 & المانجو \\
\hline
\end{tabular}

جدول 7. أهم الأسواق تقوم الثركات الحاصلة علي معايير الجودة بالتصدير إليها

\begin{tabular}{|c|c|c|c|}
\hline \multirow[b]{2}{*}{ أهم المحاصيل يتم تصديرها } & \multicolumn{2}{|c|}{ الثركات الحاصلة على معايير جودة } & \multirow[b]{2}{*}{ 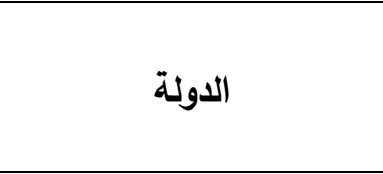 } \\
\hline & الاهمية النسبية من العينة & 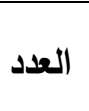 & \\
\hline البطاطس- الفراولة- الفاصوليا & 59 & 16 & دول الإتحاد الأوروبي وأمربكا \\
\hline البرتقال -المانجو - الفراولة-البصل & 30 & 8 & الدول العربية(خاصة دول \\
\hline البرتقال- البطاطس- المانجو & 7 & 2 & السوق الأسيوي بما فيها \\
\hline البرتقال - الفراولة- الفاصوليا- البصل & 4 & 1 & أسواق أخري \\
\hline
\end{tabular}

المصدر: جُمعت وحُسبت من عينة البحث.

يمثل نحو 30\% من عينة البحث، كما أشارت بيانات

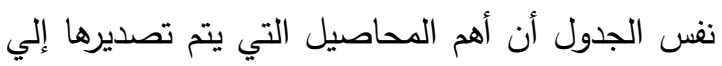

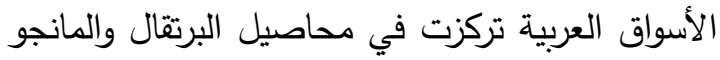
والفراولة والبصل، خاصة المملكة العربية السعودية ودولة فئل

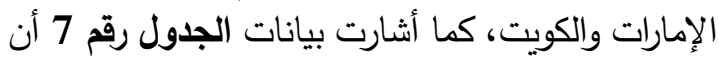

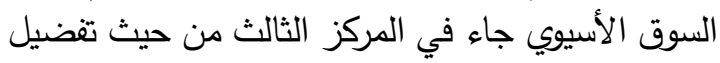

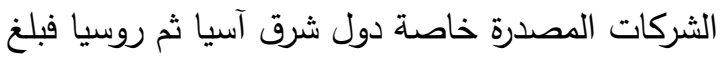
عدد المصدرين للسوق الأسيوي حوالي شركتان بما يمثل شئل
يمثل نحو 59\% من عينة البحث، كما أشارت بيانات

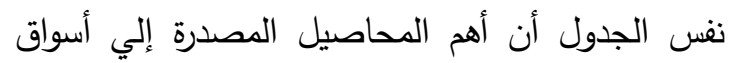
الإتحاد الأوروبي خاصة دول (المملكة المتحدة، ألمانيا،

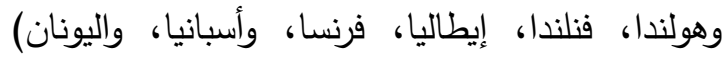

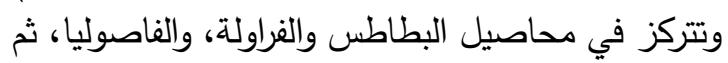

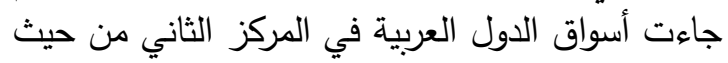

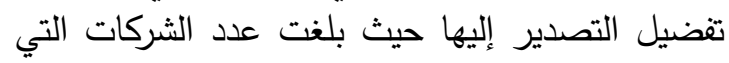
تفضل التصدير للدول العربية حوالي ثمانية شركات، بلفا 
وبدأت معظم الثركات وخاصة الغير حاصلة علي

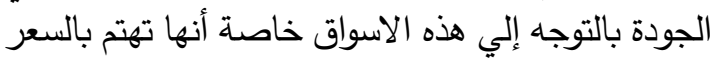

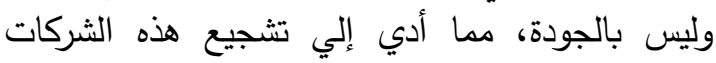

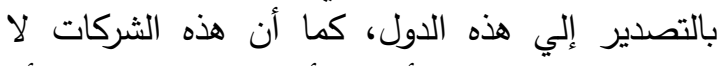

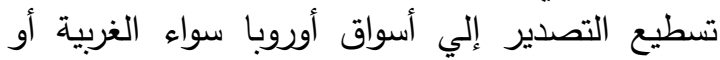

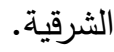

سابعاً: أثر تطبيق معايير الجودة علي الإنتاج والتصدير

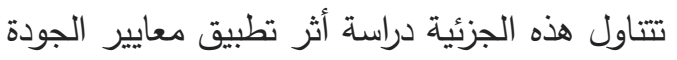

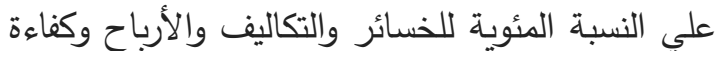
استخدام الموارد وكفاءة عملية الإنتاج وتطوير ألداء الموظفين. - المخام

\section{1- أثر تطبيق معايير الجودة علي نسبة الفاقد في المحصول} توضح بيانات الجدول رقم 8 النسبة من الإنتاج التي يتم تصديرها، ومتوسط نسبة الفرز ، ومتوسط نسبة الفاقد الندان،

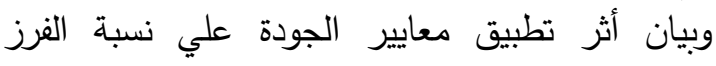
ومتوسط نسبة الفاقد، في عينة البحث من الثركات

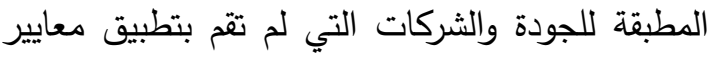
الجودة، وقد أوضحت النتائج ماً يلي: لجئ
نحو 7\% من عينة البحث، خاصة دول (ماليزيا، فيتام،

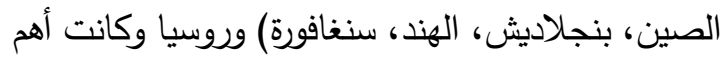

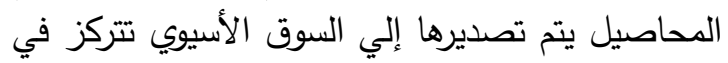
البرتقال والبطاطس والمانجو. إلا أنه خلال الفترات الأخيرة وتحديداً من منذ عام 2009 بدأ المستودين فى روسيا يهتمون بمواصفات

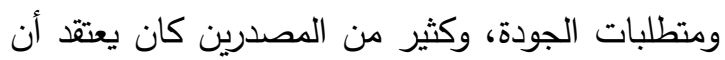

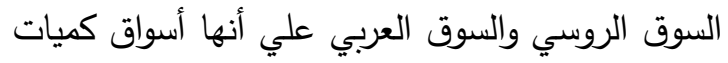

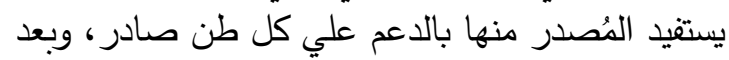
رفع الدعم عن معظم الدحاصيل التصديرية قل الاهتمام

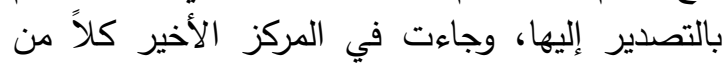

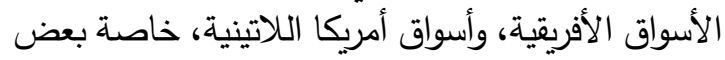

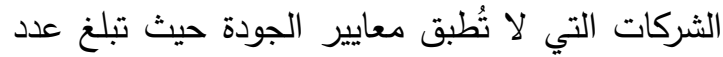

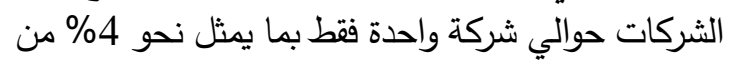
عينة البحث، حيث تلجأ هذه الشركة للدول الأفريقية ودول

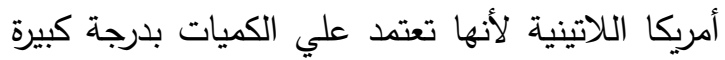

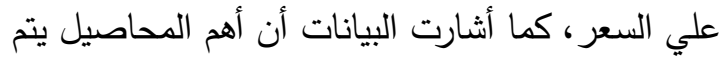

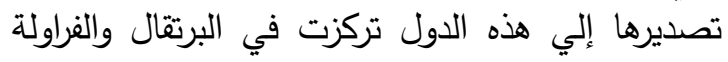

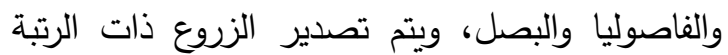

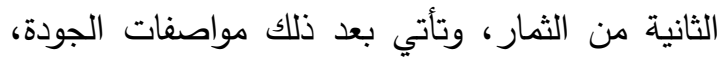

جدول 8. متوسط نسبة الصادرات ونسبة الفرز ونسبة الفاقد للشركات المطبقة والغير مطبقة لمعايير الجودة في عينة البحث

\begin{tabular}{|c|c|c|c|c|c|c|}
\hline \multicolumn{3}{|c|}{ الثركات التي لا تطبق معايير } & \multicolumn{3}{|c|}{ الشركات تُطبق معايير الجودة } & \multirow[t]{3}{*}{ البيان } \\
\hline$\%$ & $\%$ & $\%$ & $\%$ & $\%$ & $\%$ & \\
\hline الفاقد & الفرز & الصادرات & الفاقد & الفرز & الصادرات & \\
\hline 5 & 43 & 52 & 2,5 & 30 & 67,5 & البرتقال \\
\hline 6 & 44 & 50 & 3 & 32 & 65 & البطاطس \\
\hline 10 & 30 & 60 & 1,5 & 13.5 & 85 & الفراولة \\
\hline 8 & 32 & 60 & 1 & 19 & 80 & المانجو \\
\hline
\end{tabular}

المصدر : جُمعت وحُسبت من عينة البحث. 
وبلغت نسبة صادرات الفراولة في عينة البحث

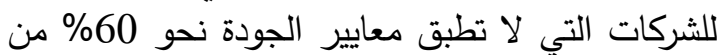

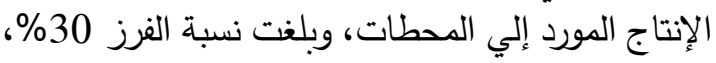
يتم توجيه بالكامل للسوق المحلي أو شركات المربات المبات والعصائر، بينما بلغ متوسط نسبة الفاقد منها نحو لـوات الفربات

\%10

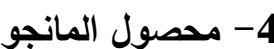

بالنسبة للشركات الحاصلة والمطبقة لمعايير الجودة توضح بيانات الجدول رقم 8 أن متوسط نسبة صادية صادرات

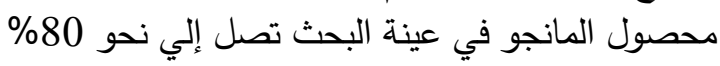

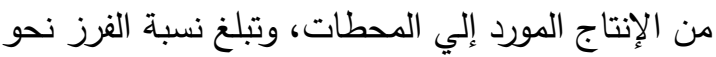

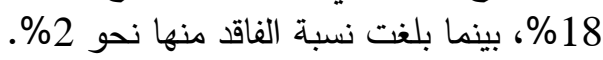
بينما بلغت نسبة الصادرات في عينة البحث للشركات التي لا تطبق معايير الجودة 60\% من الإنتاج المورد إلي المحطات، بينما بلغت نسبة الفرز نحو

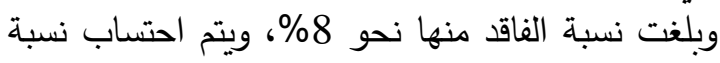

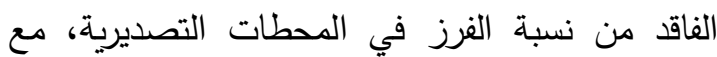

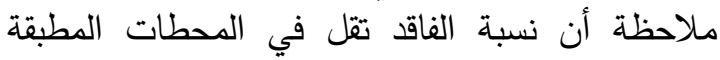
لمعايير الجودة ويرجع ذلك إلي وجود مندوب إدارة الجودة

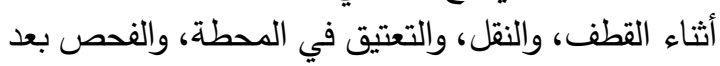

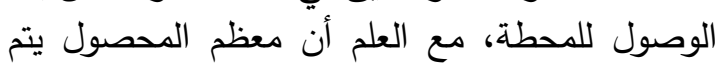
تصديره من الأرض مباشرة.

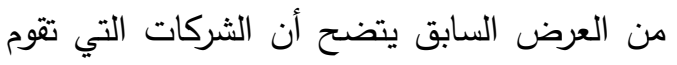
بتطبيق معايير الجودة في الإنتاج والتسويق ترتفع فيها

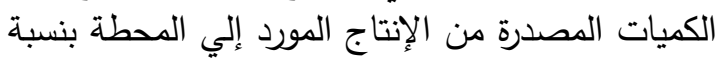

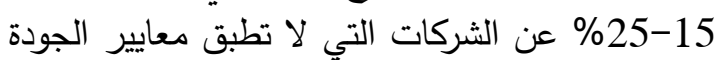

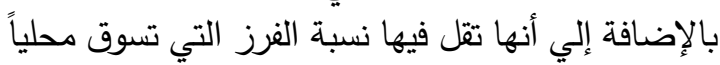

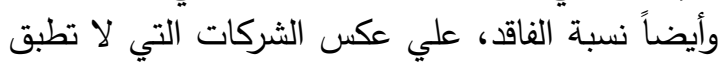

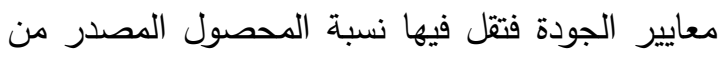

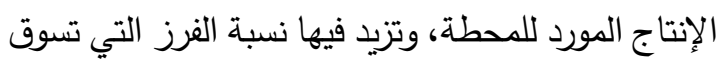

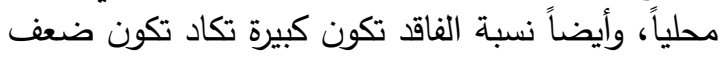
الفاقد في الثركات تُطبق معايير الجودة، الأمر الذي نُوني

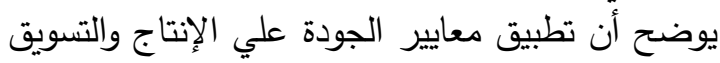
بهدف التصدير يعمل علي تطوير وزيادة الصادرات

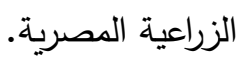

1- 1 - 1حصول البرتقال

بالنسبة للشركات الحاصلة والمطبقة لمعايير الجودة

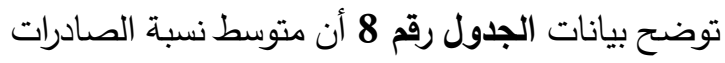

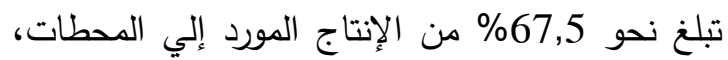

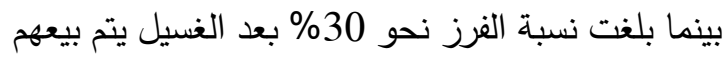

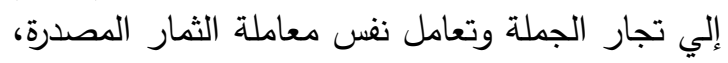

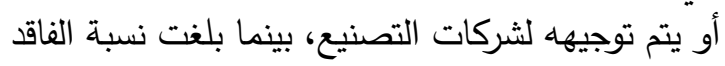
نحو 2,5\%. كما يتضح من بيانات نفس الجدول بالنسبة للشركات

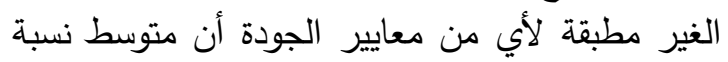

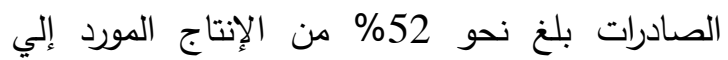

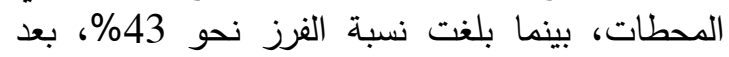

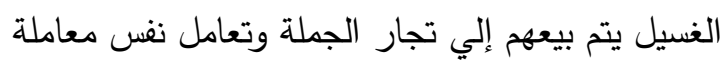
الثمار المصدرة، بينما بلغت نسبة الفاقد نحو 5.

\section{2- 2- محصول البطاطس}

بالنسبة للشركات الحاصلة والمطبقة لمعايير الجودة

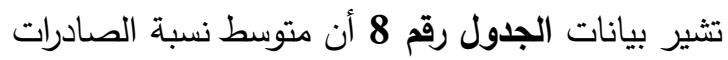

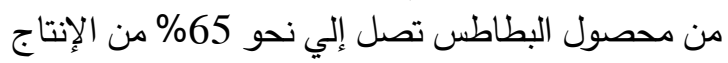

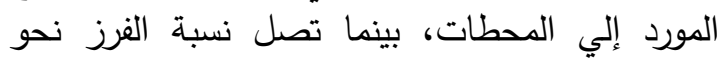

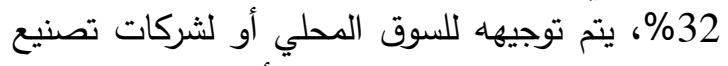

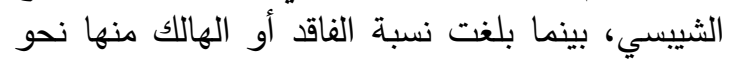

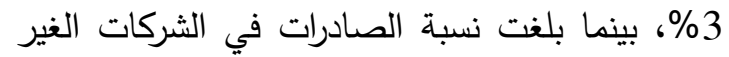

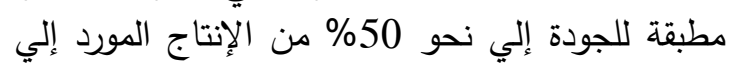

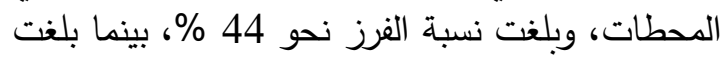

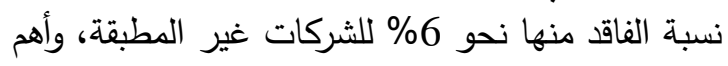
الأصناف التي يتم تصديرها للخارج هي (الأسبونتا،

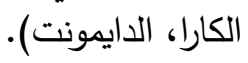

\section{3- محصول الفراولة}

بالنسبة للشركات الحاصلة والمطبقة لـعايير الجودة

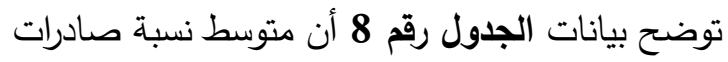

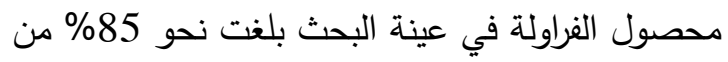

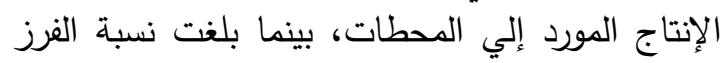

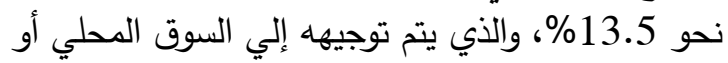

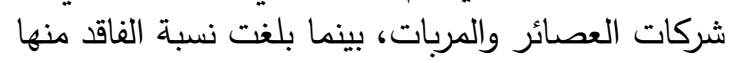
نحو 1,5\% وذلك في عينة البحث للشركات المطبقة

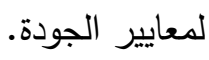


3- أثر تطبيق معايير الجودة علي الأرباح والإنتاج في عينة البحث

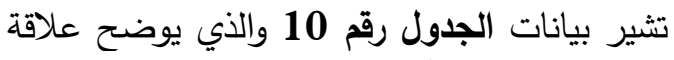
معايير الجودة بزيادة أرباح الثركات مع زيادة الحصة ولتاء

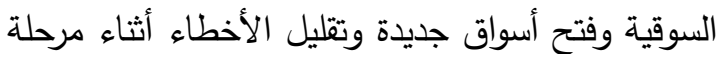

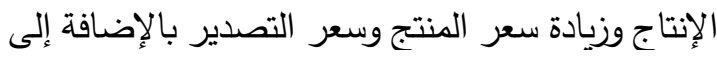

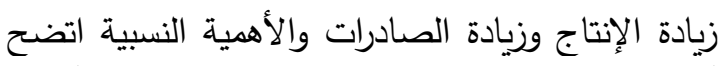

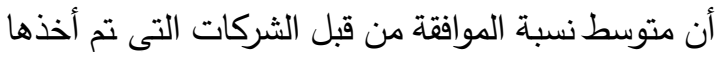

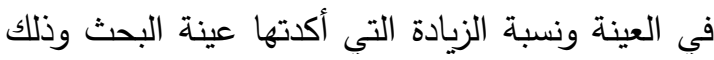
علي البنود التي تصف ونيلة أبعاد الجودة وهي: جدول 10. أثر تطبيق معايير الجودة علي الأرباح

\begin{tabular}{|c|c|c|c|}
\hline نسبة & لعينة & عدات & أثر التطبيق \\
\hline$\% 25$ & $\% 60$ & 18 & زبادة أرباح الشركة \\
\hline$\% 30$ & $\% 57$ & 17 & التقليل $\quad$ الإنتاء $\quad$ الأخطاء \\
\hline $\begin{array}{r}-10 \\
\% 15\end{array}$ & $\% 53$ & 16 & أسيادة $\quad$ السوقية $\quad$ الحصة \\
\hline$\% 30$ & $\% 47$ & 14 & التصدير $\quad$ سعر \\
\hline$\% 20$ & $\% 47$ & 14 & زيادة سعر المنتج \\
\hline $\begin{array}{r}-15 \\
\% 20\end{array}$ & $\% 53$ & 16 & زيادة الإنتاج \\
\hline$\% 35$ & $\% 53$ & 16 & زبادة الصادرات \\
\hline$\% 26$ & $\% 53$ & - & المتوسط* \\
\hline
\end{tabular}
(*) المتوسط الهندسي للنسب المئوية. المصدر: جمعت وحسبت: من استمارة الإستبيان بعينة • حيث، أكد نحو 60\% من عينة البحث أن تطبيق معايير الجودة أدت إلى زيادة أرباح الثركات بنسبة تبلغ النغ نان نحو 25\%. نمعاير الجودة • • جاء في المركز الثاني نسبة تقليل الأخطاء حيث أكد

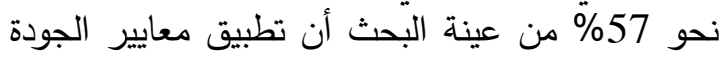
أدت إلي تقليل الأخطاء أثناء مرحلة الإنتاج بنسبة تبلغ أنغ الغن
2- أثر تطبيق معايير الجودة علي التكاليف

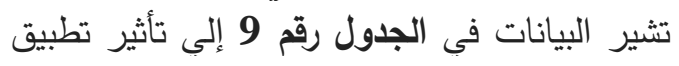
معايير الجودة علي التكاليف، حيث يتضح من عينة

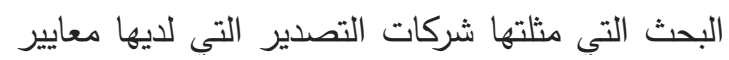

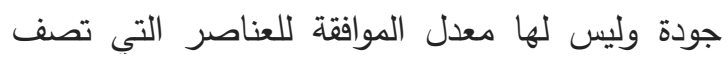
العلاقة بين التكاليف والتطبيق من معايير الجودة بلغت التعائ

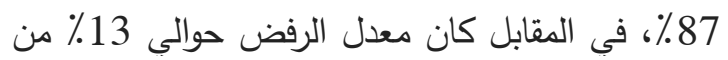

إجمالي العينة، وكانت العناصر علي النحان النحو التالي:

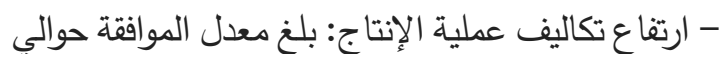

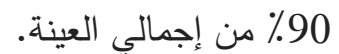
- ارتفاع تكاليف الخدمات والعمليات التسويقية: وهي

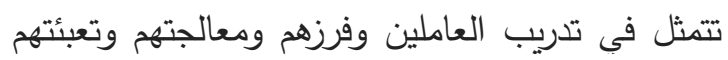

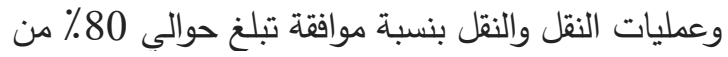
إجمالي عينة البحث. - أجور عالية: بدءاً من أجور العاملين في الزراعة

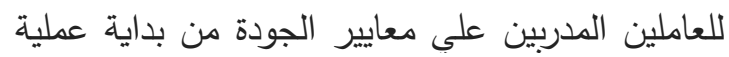
الإنتاج إلي عملية التصدير ، بمعدل موافقة يبلغ حوالي لئي

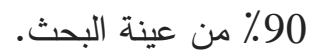

جدول 9. أثر تطبيق معايير الجودة علي التكاليف في

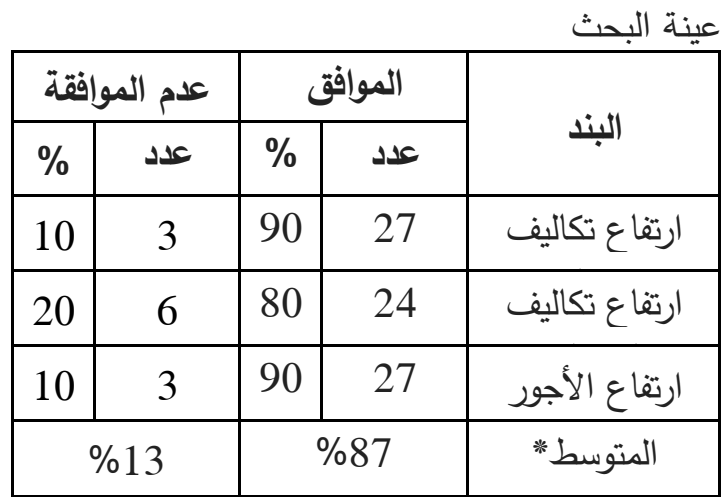
* متوسط هندسي للنسب المئوية. المصدر: جُمعت وحُسبت من استبيان البحث الميداني في

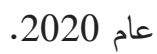

يتضح مما سبق أن تطبيق معايير الجودة يؤدي إلي الي التي زيادة التكاليف، خاصة في المراحل الأولي من التطبيق،

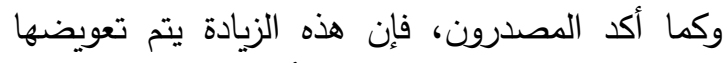

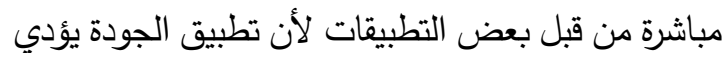
إلي تخفيض نسبة الخسائر بالإضافة إلي زيادة الأرباح

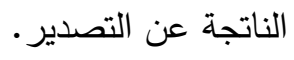


الوسط الفرضى للمقارنة بين الثركات تُطبق معايير الجودة والثركات لم تُطبقها.

1- محصول البرتقال: توضح بيانات الجدول رقم 11

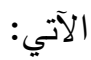
- ارتفاع الإنتاجية الفدانية لمحصول البرتقال في مزارع

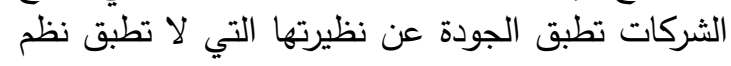

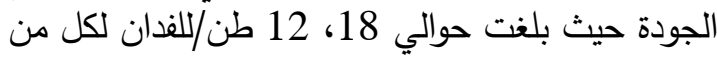
مزارع الثركات طبقت معايير الجودة والثركات لم تُطبقها علي الترتيب، وقد ثبتت معنوية هذه الزيادة عند 0.01

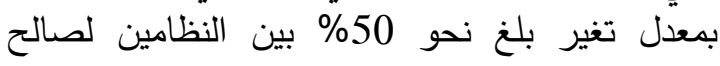
الشركات طبقت معايير الجودة. - تشير بيانات الجدول رقم 11 إلي البئ ارتفاع تكاليف

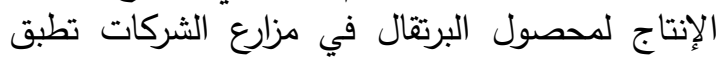

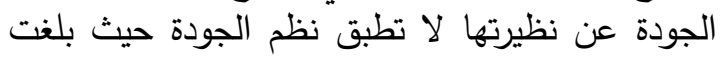

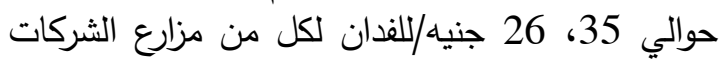

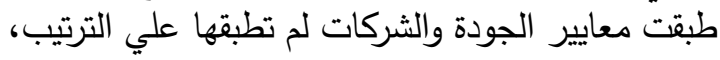

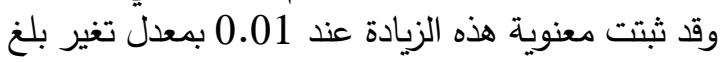

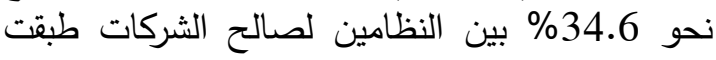

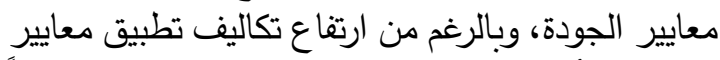

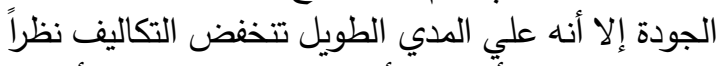

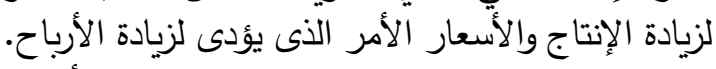

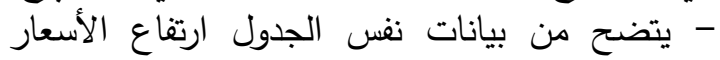

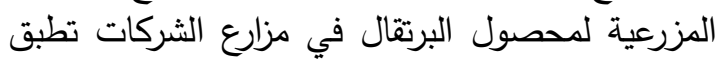

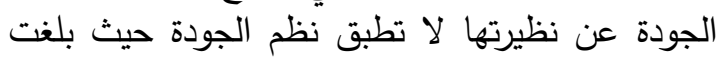

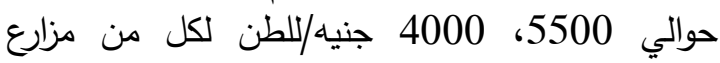

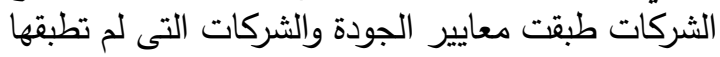

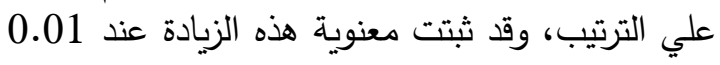

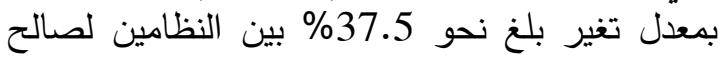
الشركات طبقت معايير الجودة. - كما يتضح زيادة الأرباح لمحصول التصود البرتقال في مزارع

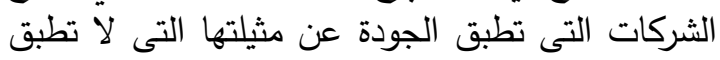

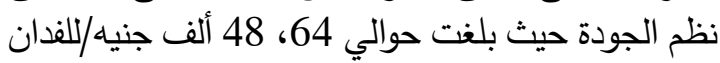

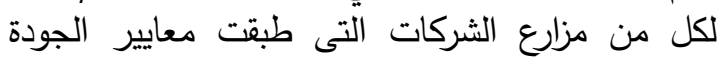

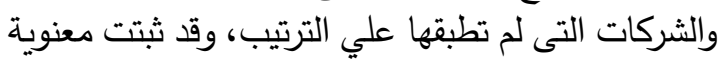

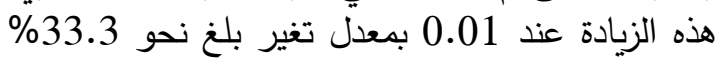
بين النظامين لصالح الثركات التى طبقت بنت معايير

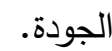

- تشير بيانات الجدول رقم 11 أن عائد الجنيه علي

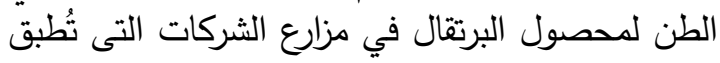

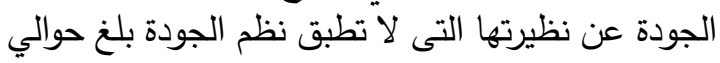

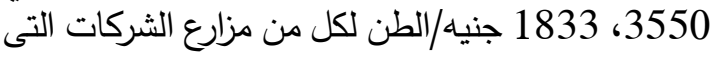

نحو 30\%، وذلك لزيادة المراقبة في المراحل الأولي من

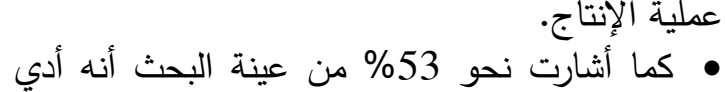
لزيادة الحصة السوقية وفتح أسواق جديدة بنسبة البحث نحو أندي \% 14 • كما أكد نحو 47\% عينة البحث أنه بتطبيق معايير

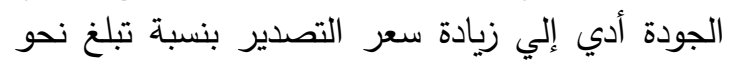

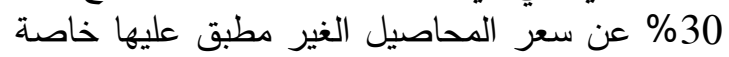
أنها تكون تحت مراقبة الجهات المستوردة وتكون تكلفتها أعلي. • كما أشارت النتائج التي تم التوصل إليها من خلال

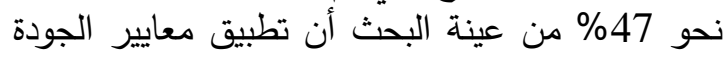

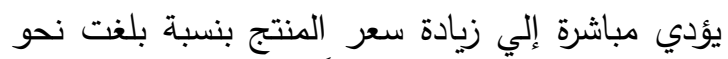

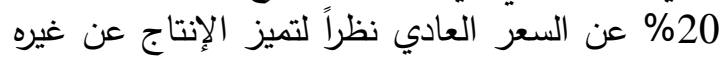
من الإنتاج العادي. • بالإضافة إلي تأكيد نحو 53\% من العنادي.

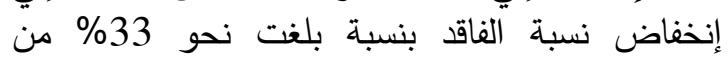
المحصول الأمر الذي ينعكس بدوره علي زيادة الإنتاج

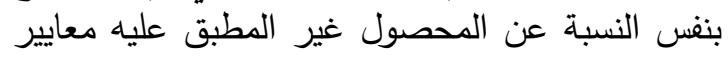

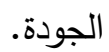
• كما اشار نحو 53\% من عينة البحث أن زيادة

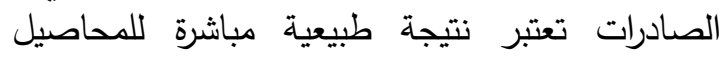

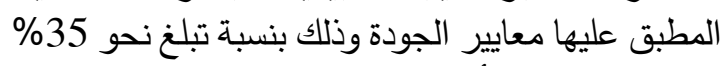

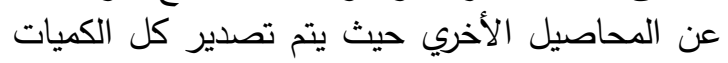

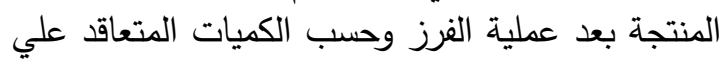

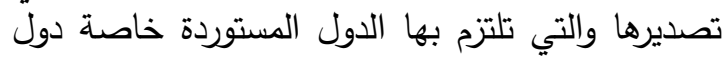
الإتحاد الأوروبي. تصني

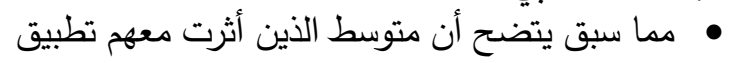

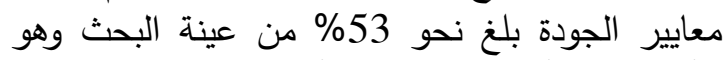

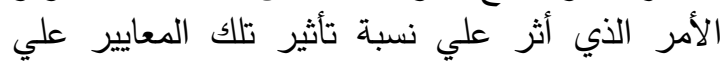

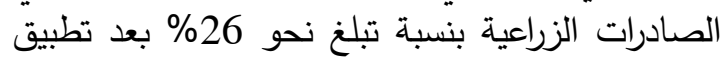
المعايير علي المحاصيل الزراعية.

4- الأثر الفعلي لتطبيق معايير الجودة علي المحاصيل من خلال عينة "البحث التطيق تتتاول هذه الجزئية دراسة الأثر الفعلى لتطبيق

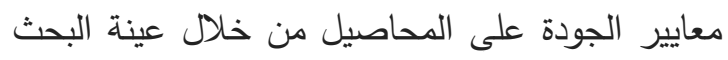
وذلك من خلال تحليل التباين واختبار (T) ومعدل التئل التغير

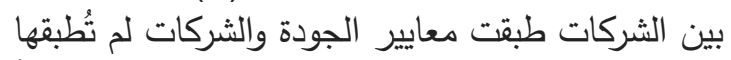
وأثر ذلك على الإنتاج والتكاليف والأسعار والأرباح وأخيراً العائد علي الطن لمحاصيل البحث وذلك ولك باستخدام 


\begin{tabular}{|c|c|c|c|c|c|}
\hline \multirow{2}{*}{ التغير معدل } & \multirow{2}{*}{$t$-test } & \multirow{2}{*}{ الانحراف } & \multirow{2}{*}{ بعد تطبيق الجودة } & \multirow{2}{*}{ قبل تطبيق الجودة } & \multirow{2}{*}{ المتغيرات } \\
\hline & & & & & \\
\hline 50 & $* * 17$ & 1.4 & 18 & 12 & الإنتاج (طن/فدان) \\
\hline 34.6 & $* * 14.9$ & 2.4 & 35 & 26 & التكاليف (بالألف جنيه) \\
\hline 37.5 & $* * 12.3$ & 4.3 & 5500 & 4000 & الأسعار (بالجنيه/للطن) \\
\hline 33.3 & $* * 88.8$ & 2 & 64 & 48 & الأرباح (بالألف جنيه) \\
\hline 93.7 & $* * 111.6$ & 61.5 & 3550 & 1833 & عائد الجنيه علي الطن \\
\hline
\end{tabular}

"متوسط المجتمع طبقاً لبيانات وزارة الزراعة واستصلاح الأراضى.

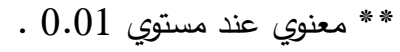

المصدر: جمعت وحسبت من استمارات الاستبيان .

- يتضح من بيانات نفس الجدول ارتفاع الأسعار

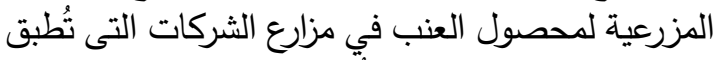

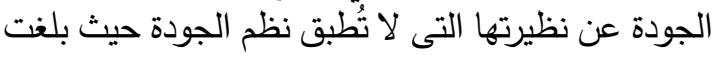

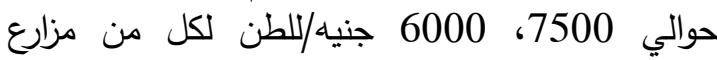
الثركات التى طبقت معايير الجودة والشركات التى لـ لم

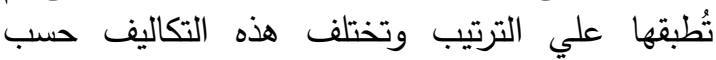
الأصناف، وقيد ثبتت معنوية هذه الزيادة عند 0.01

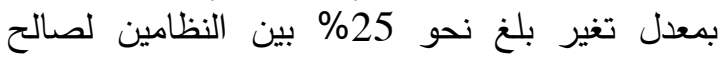
الشركات التى طبقت معايير الجودة.

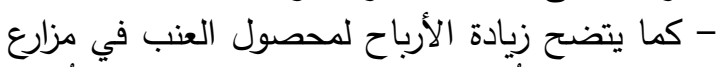

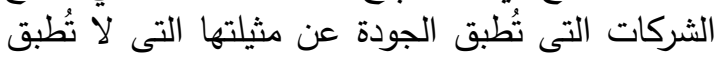

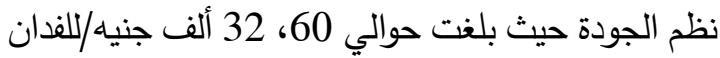

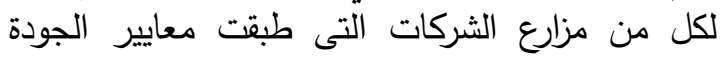

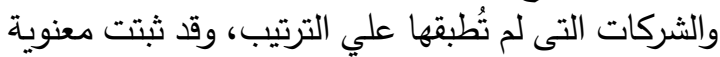

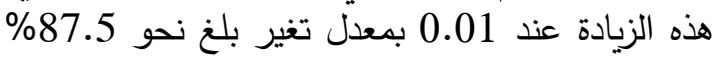
بين النظامين لصالح الشركات التى طبقت بنت معايير

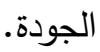
- تشير بيانات الجدول رقم 12 أن عائد الجنيه علي

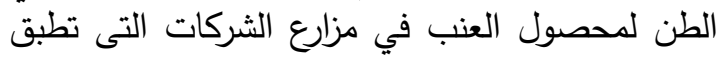

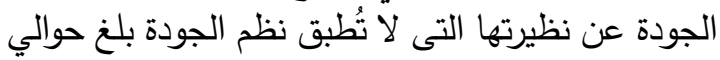

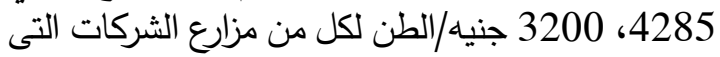

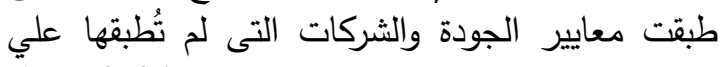

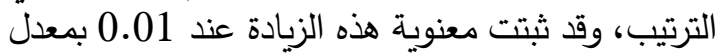

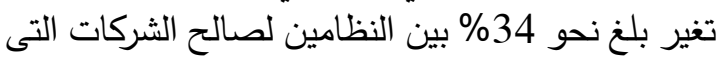
طبقت معايير الجودة.
طبقت معايير الجودة والثركات التى لم تطبقها علي

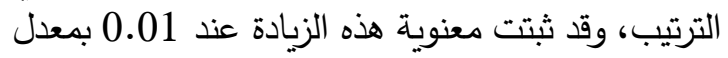
تغير بلغ نحو 93.7\% بين النظامين لصالح الشركات التى طبقت معايير الجودة. محصول العنب: توضح بيانات الجدول رقم 12 الآتي:

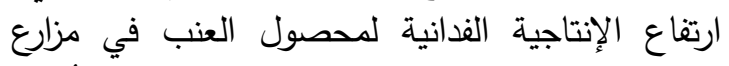

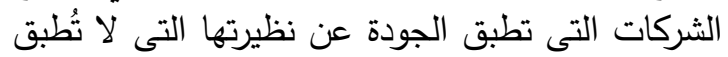

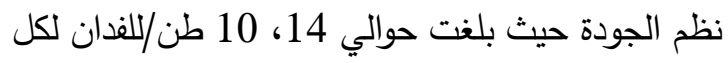

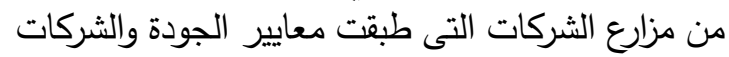

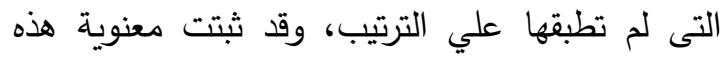

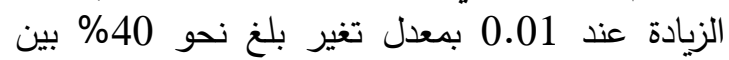
النظامين لصالح الثركات التى طبقت معايير الجودة.

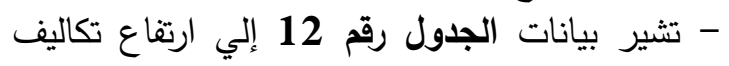

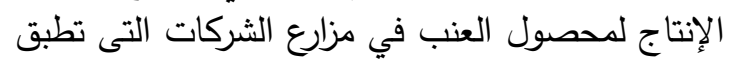

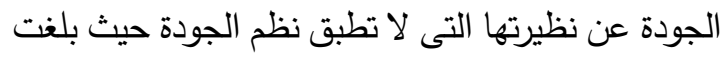

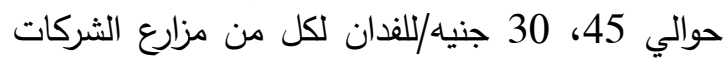

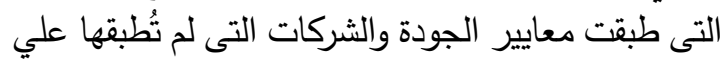

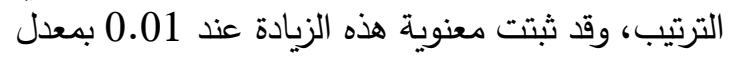

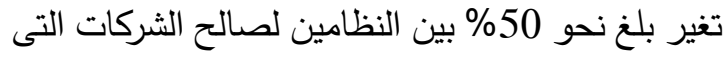

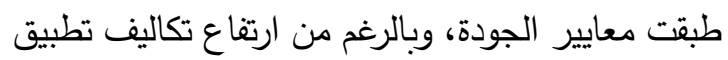

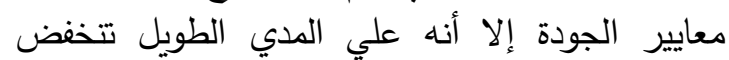

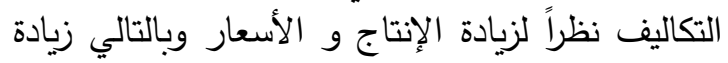

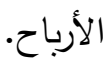


جدول 12. الأثر الفعلي لتطبيق معايير الجودة علي محصول العنب من خلال عينة البحث

\begin{tabular}{|c|c|c|c|c|c|}
\hline \multirow{2}{*}{ التغير معدل } & \multirow{2}{*}{$t-$ test } & \multirow{2}{*}{ الانعراف } & بعد تطبيق الجودة & قبل تطبيق الجودة & \multirow{2}{*}{ المتغيرات } \\
\hline & & & المتوسط & المتوسط" & \\
\hline 40 & $* * 13.7$ & 1.2 & 14 & 10 & الإنتاج (طن/فدان) \\
\hline 50 & $* * 38.7$ & 1.5 & 45 & 30 & التكاليف (بالألف جنيه) \\
\hline 25 & $* * 38.2$ & 146.7 & 7500 & 6000 & الأسعار (بالجنيه/للطن) \\
\hline 87.5 & $* * 39.7$ & 3 & 60 & 32 & الأرباح (بالألف جنيه) \\
\hline 34 & $* * 17$ & 258.8 & 4285 & 3200 & عائد الجنيه علي الطن \\
\hline
\end{tabular}

"متوسط المجتمع طبقاً لبيانات وزارة الزراعة واستصلاح الأراضى.

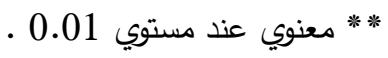
المصدر : جمعت وحسبت من استمارات الاستبيان .

تُطبق الجودة عن نظيرتها التى لا تُطبق نظم الجودة

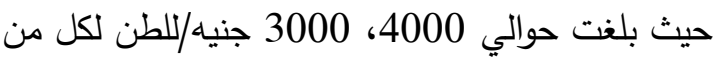

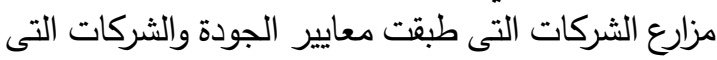

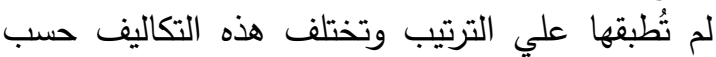
الأصناف، وقد ثبتت معنوية هذه الزيادة ونئ عند 0.01

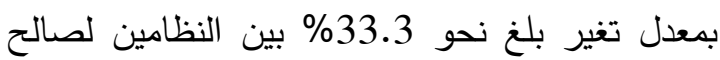
الثركات التى طبقت معايير الجودة.

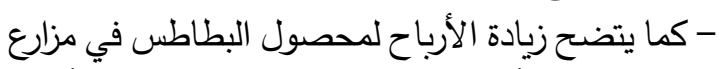
الشركات التى تُطبق الجودة عن مثيلتها لا لا التى تُطبق

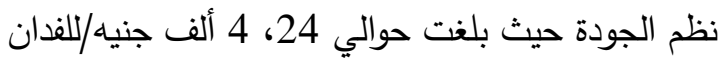

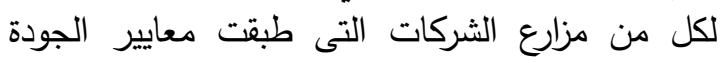

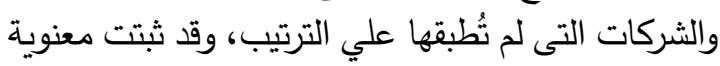

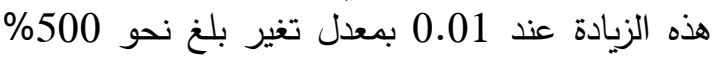

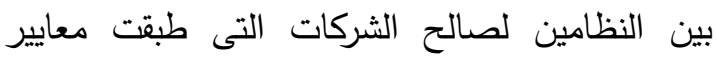
الجودة، ويرجع ارتفاع الأرباح بهذه النسبة نظات لنظراً لأن

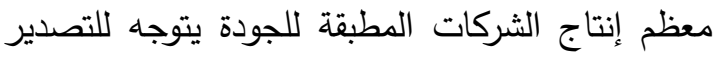

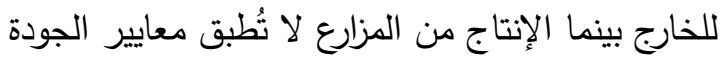

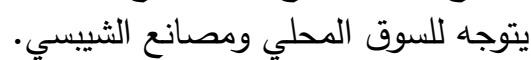

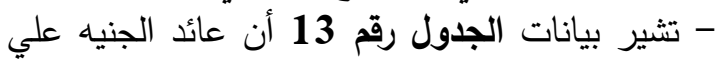
الطن لمحصول البطاطس في مزارع الثركات التى تُطبق الجيق

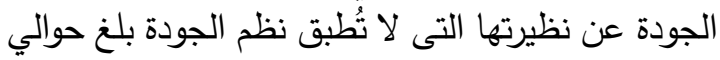

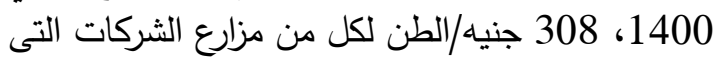

3- محصول البطاطس: توضح بيانات الجدول رقم 13

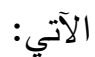
- ارتفاع الإنتاجية الفدانية لمحصول البطاطس في مزارع

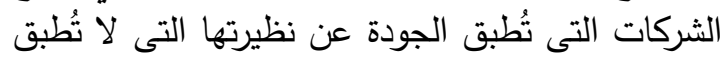

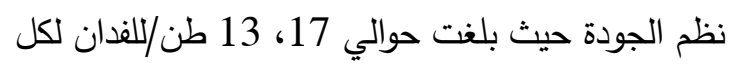
من مزارع الشركات التى طبقت معايير الجودة والثركات

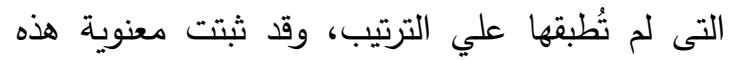

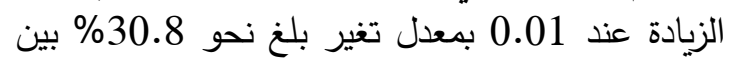
النظامين لصالح الشركات التى طبقت معايير الجودة.

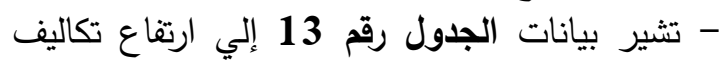

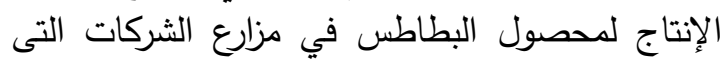

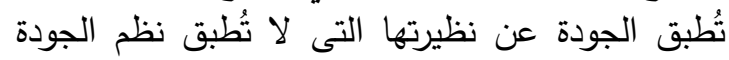

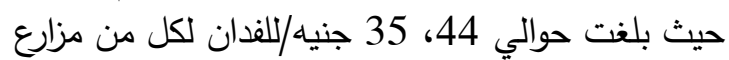
الشركات التى طبقت معايير الجودة والثركات التى لـ لم

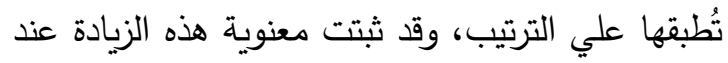

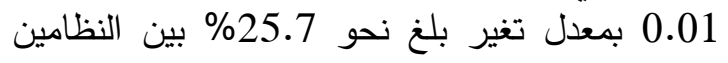

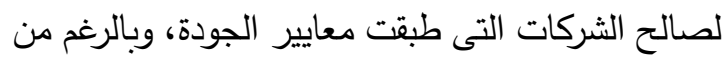
ارتفاع تكاليف تطبيق معايير الجودة إلا أنه علي المدي لإني

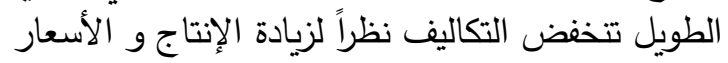
وبالتالي زيادة الأرباح. - يتضح من بيانات نفس الجدول التبات ارتفاع الأسعار

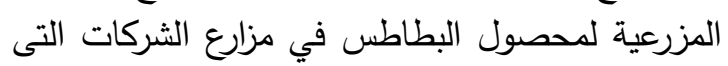


جلول 13. الأثر الفعلي لتطبيق معايير الجودة علي محصول البطاطس من خلال عينة البحث

\begin{tabular}{|c|c|c|c|c|c|}
\hline \multirow{2}{*}{ التغير معدل } & \multirow{2}{*}{$t-$ test } & الانحراف & بعد تطبيق الجودة & قبل تطبيق الجودة & \multirow{2}{*}{ المتغيرات } \\
\hline & & المعياري & المتوسط & المتوسط* & \\
\hline 30.8 & $* * 11.3$ & 1.4 & 17 & 13 & الإنتاج (طن/فدان) \\
\hline 25.7 & $* * 15.2$ & 2.4 & 44 & 35 & التكاليف (بالألف جنيه) \\
\hline 33.3 & $* * 13.6$ & 293 & 4000 & 3000 & الأسعار (بالجنيه) \\
\hline 500 & $* * 40$ & 2 & 24 & 4 & الأرباح (بالألف جنيه) \\
\hline 355 & $* * 63.7$ & 72.7 & 1400 & 308 & عائد الجنيه على الطن \\
\hline
\end{tabular}

"متوسط المجتمع طبقاً لبيانات وزارة الزراعة واستصلاح الأراضى.

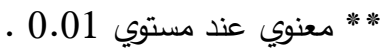
المصدر : جمعت وحسبت من استمارات الاستبيان .

- يتضح من بيانات نفس الجدول ارتقاع الأسعار

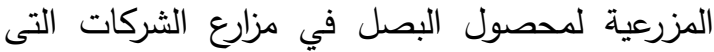

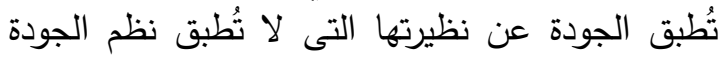

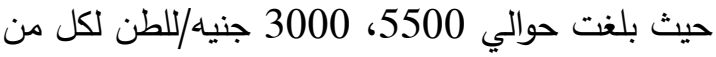

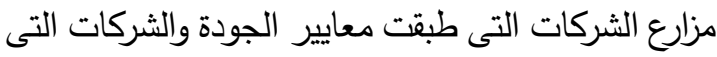
لم تُطبقها علي الترتيب وتختلف هذه التكاليف حسب التب الأصناف، وقد ثبتت معنوية هذه الزيادة عند 0.01

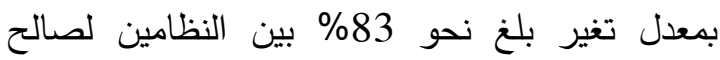
الشركات طبقت معايير الجودة.

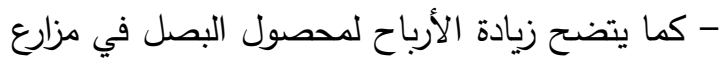

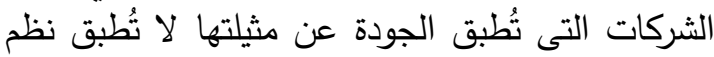

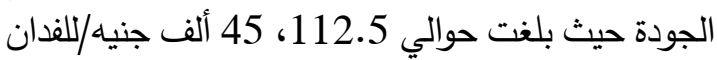
لكل من مزارع الثركات التى طبقت معايير الجودة

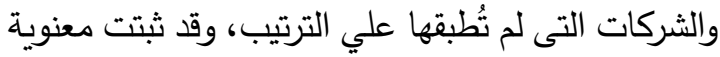

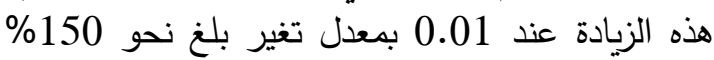
بين النظامين لصالح الثركات التى طبقت بنت معايير

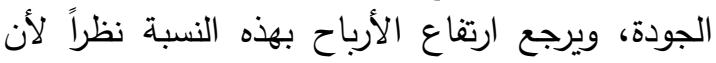

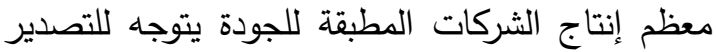

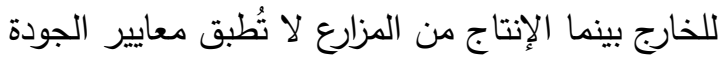
يتوجه للسوق المحلي ومصانع الثيبسي.

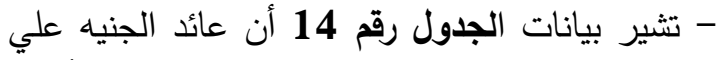

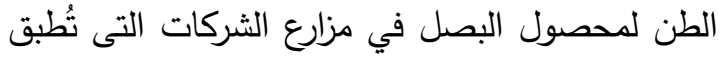

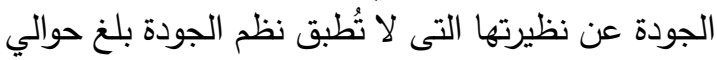

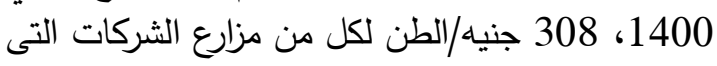
طبقت معايير الجودة والثركات لم تُطبقها علي الترتيب، للتركات التى
طبقت معايير الجودة والثركات التى لم تُطبقها علي الترتيب، وقد ثبتت معنوية هذه الزيادة عند 0.01 بمعدل

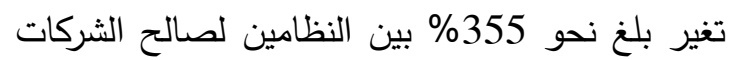
التى طبقت معايير الجودة.

4- محصول البصل: توضح بيانات الجدول رقم 14

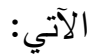
- ارتفاع الإنتاجية الفدانية لمحصول البصل في مزارع

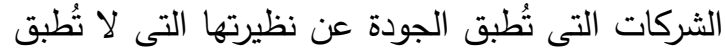

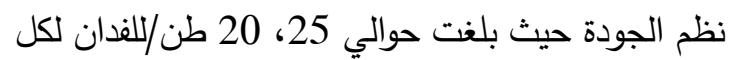
من مزارع الشركات التى طبقت معايير الجودة والشركات

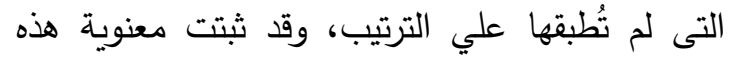

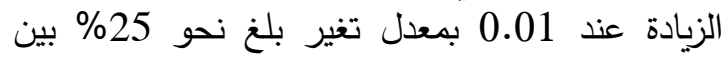
النظامين لصالح الشركات التى طبقت معايير الجودة.

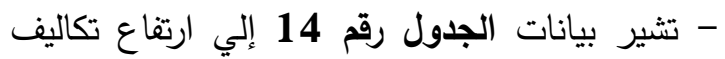

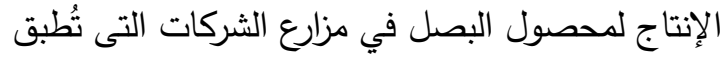

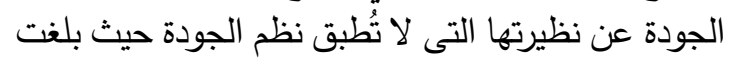

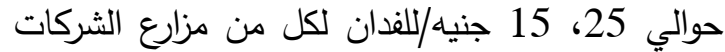

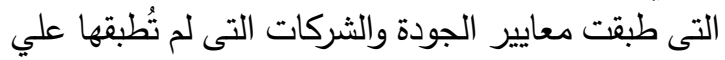
الترتيب، وقد ثبتت معنوية هذه الزيادة عند 0.01 بمعدل

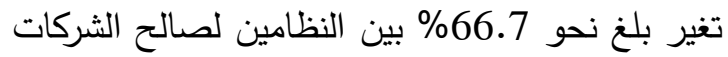

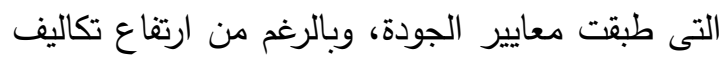

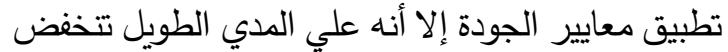
التكاليف نظراً لزيادة الأسعار وبالتالي زيادة الأبراح. 
جدول 14. الأثر الفعلي لتطبيق معايير الجودة علي محصول البصل من خلال عينة البحث

\begin{tabular}{|c|c|c|c|c|c|}
\hline معدل معل & $t-$ test & الانحراف & |بعد تطبيق الجودة & قبل تطبيق الجودة & المتفرات \\
\hline التغير\% & & المعياري & |لمتوسط & المتوسط" & \\
\hline 25 & $* * 10.4$ & 1.9 & 25 & 20 & الاتتاج (طن/فدان) \\
\hline 66.7 & $* * 20.7$ & 1.9 & 25 & 15 & التكاليف (بالألف جنيه) \\
\hline 83 & $* * 18.5$ & 487 & 5500 & 3000 & الأسعار (بالجنيه) \\
\hline 150 & $* * 3.7$ & 87.4 & 112.5 & 45 & الأرباح (بالألف جنيه) \\
\hline 100 & $* * 19.6$ & 447 & 4500 & 2250 & عائد الجنيه علي الطن \\
\hline
\end{tabular}

"تمتوسط المجتمع طبقاً لبيانات وزارة الزراعة واستصلاح الأراضى.

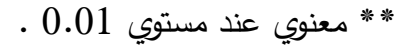

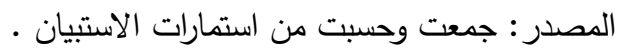

ويعزي ذلك لزيادة تكلفة تطبيق نظم الجودة أو أنها في غالبية نشاطها تقوم بعملية الوساطة فقط ما بين المنتجين وشركات التصدير الكبري.

5- أثر تطبيق معايير الجودة علي كفاءة استغلال الموارد وكفاءة العمليات الإنتاجية وتطوير أداء العاملين

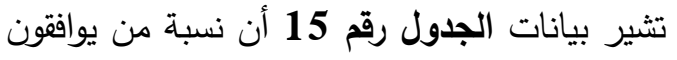
أن أثر تطبيق الجودة علي كافة العمليات الإنتاجية تكاد

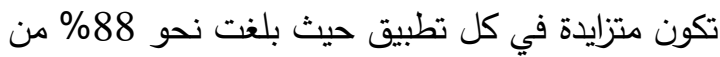
عينة البحث وهذا يرجع أن الثركات التي تدرك تأثلثي

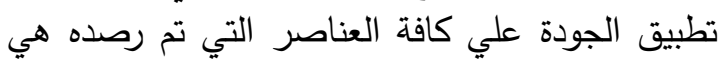
شركات لها خبرة في تطبيق الجودة من الأصل وبالتالي الجي

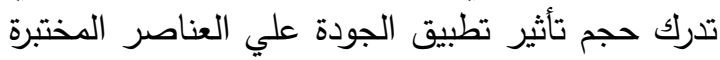

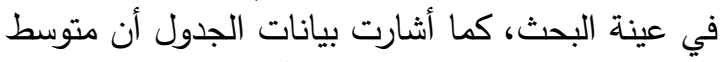

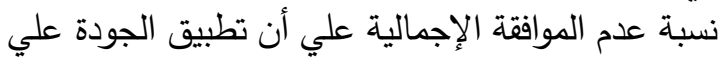

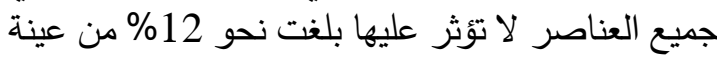

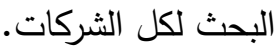

6-أثر تطبيق معايير الجودة علي تدريب العاملين: يتضح من بيانات الجدول رقيم 15 أندائه بتطبيق

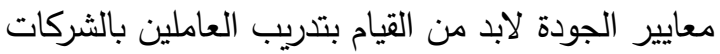

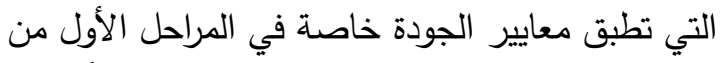
التطبيق، وبالرغم من هذا يؤدي لزيادة التكلفة إلا أنه بعد دن التيد
وقد ثبتت معنوية هذه الزيادة عند 0.01 بمعدل تغير بلغ المبات نحو 100\% بين النظامين لصالح الثركات التى طبقت نئر معايير الجودة. مما سبق وعلي ضوء النتائج السابقة يكون هناك تأثير إيجابي لتطبيق نظم الجودة علي الإنتاجية الفدانية وبالتالي الإنتاج الكلي بالإضافة للألثثر الإيجابي علي الإني

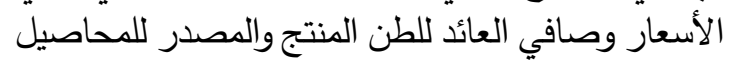

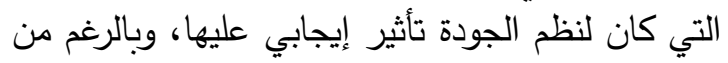

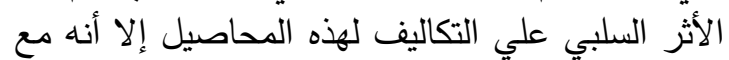
زيادة الإنتاجية والأرباح لهذه المحاصيل بعد التطبيق

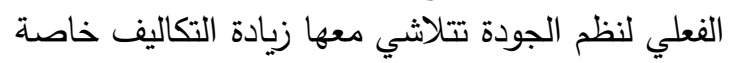
علي المدي الطويل بعد تطبيق نظم الجودة مما ئولئي

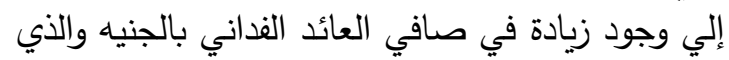
يرجع إلي وجود تغير في الانتاجية الفدانية ، هذانية

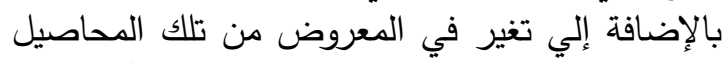
بالسوق الدحلي والسوق الخارجي وبالتالي التأثير علي الكيلي الكمية الدصدرة من تلك السلع مما يؤدي إلي وجود زيادة التئي في هيكل التجارة الخارجية بصفة عامة ونسبة لونسة تغطية الصادرات للواردات بصفة خاصة.

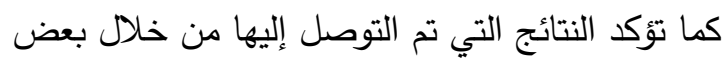

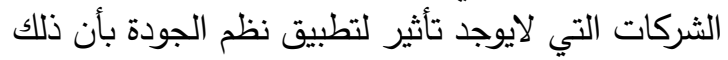

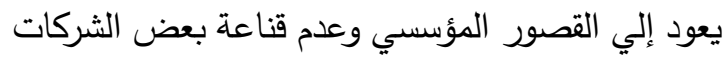
العاملة في قطاع التصدير بفكرة الإلتزام بمعايير الجودة بلتئ 
- أثر تطبيق معايير الجودة علي تقليل نسبة الخطأ:

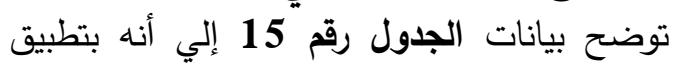

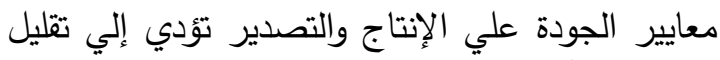

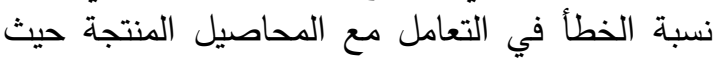
بلغت نسبة الموافقة نحو 87\% من عينة عينة البحث وذلك الكئ

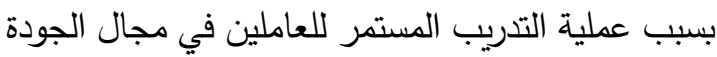

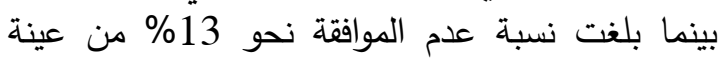

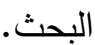

- أثر تطبيق معايير الجودة علي تقليل نسبة الفاقد

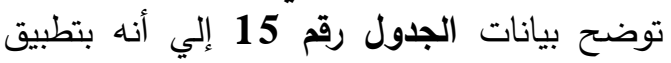
معايير الجودة علي الإنتاج والتصدير تؤدي إلي تقليل نسبة الفاقد في المحصول حيث بلغت نسبة الموافقة نحئ نحو 87 من عينة البحث بينما بلغت نسبة عدم الموافقة نحو 13\% من عينة البحث.

- أثر تطبيق معايير الجودة علي التطوير المستمر للمؤسسة اتلمبن من خلال إتخاذ الإجراءات والقرارات الصحيحة وفي

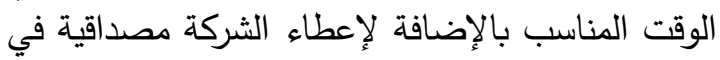
السوق الداخلي والخارجي فقد أشارت بيانات الجدول رقان

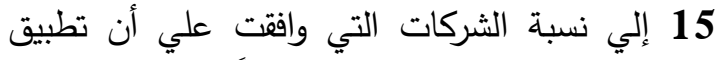

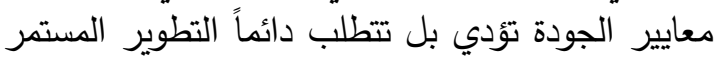

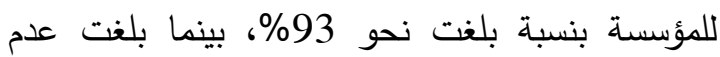

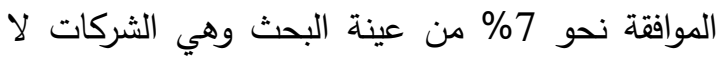
تُطبق معايير الجودة.

ثامناً: المشكلات التي تواجه المصدرين ومواصفات الجودة المطلوبـة يتتاول هذا الجزء من البحث تحديد أهم المشكلات

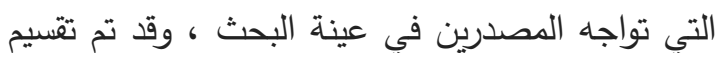

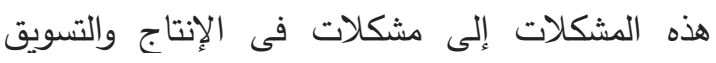
والتمويل، ومشكلات تتعلق بتطبيق معايير الجودة.

1- - 1 - مشاكل الإنتاجية يوضح الجدول رقم 16 الأهمية النسبية لأهم

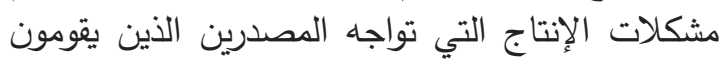

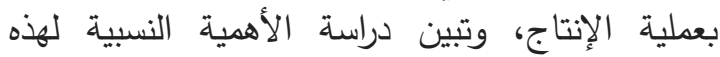
المشكلات أن مشكلة تذبذب الإنتاج المحلي تمثل حوالي
التطبيق يمكن تعويض زيادة التكلفة عن طريق زيادة

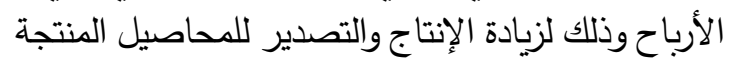
حيث بلغت نسبة الموافقة نحو 80\% من الإنتاج وذينة البحث وذلك بسبب عملية التدريب المستمر للعاملين في مجال

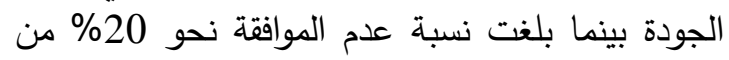

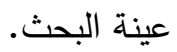

7-أثر تطبيق معايير الجودة علي التوصيف الوظيفي للعاملين تشير بيانات الجدول رقم 15 إلي أنه بتطبيق معايير

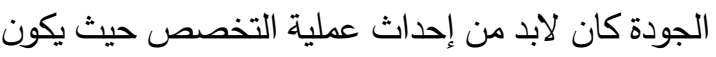

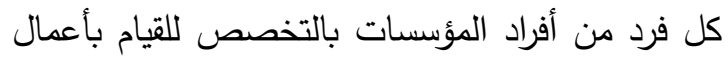

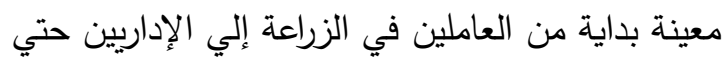

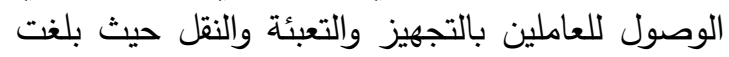

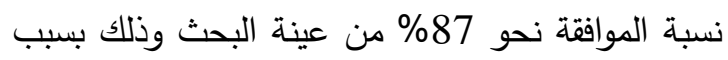

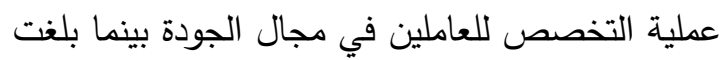
نسبة عدم الموافقة نحو 13\% من عينة البحث.

8-أثر تطبيق معايير الجودة علي إستغلال الموارد تشير بيانات الجدول رقم 15 إلي أنه بتطبيق معايير

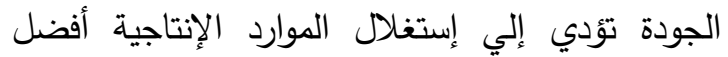
إستغلال بسبب عملية التركز والتخصص التصدي في الإنتاج والمراقبة المستمرة من جانب الجهاز الإداري والفني لهذه

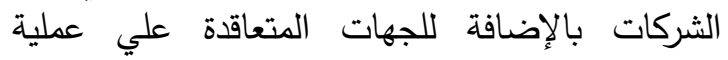
التصدير حيث بلغت نسبة الموافقة نحو 93\% بالفية من عينة

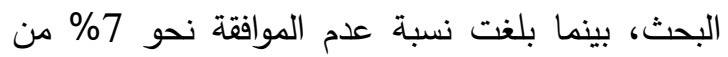
عينة البحث وهي الشركات التي لم تطبق معايير الجودة أو الغير حاصلة عليها.

9- أثر تطبيق معايير الجودة علي كفاءة العملية الإنتاجية تشير بيانات الجدول رقم 15 إلي أنه بتطبيق معايير

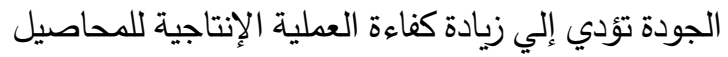

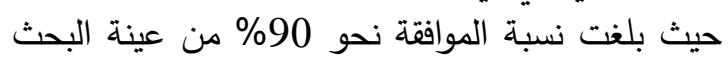
وذلك بسبب عملية التدريب المستمر للعاملين في مجال

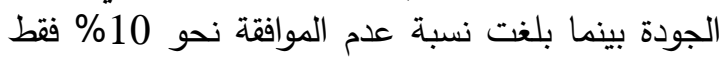

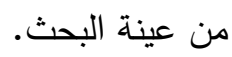


2- مشاكل التسويق يوضح الجدول رقم 17 الأهمية النسبية لأهم التهويق مشكلات التسويق التي تواجه المصدرين في عينة البحث، وتبين أن مشكلة ارتفاع تكاليف النقل لتوكئ لـيناء

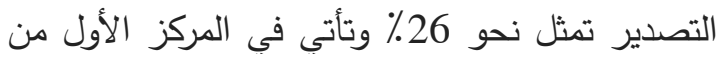

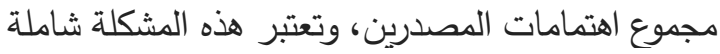

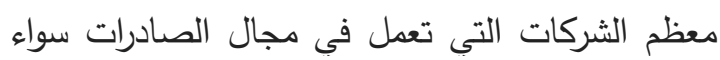

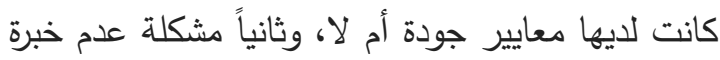

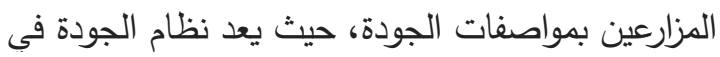

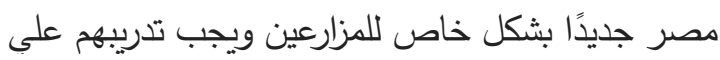

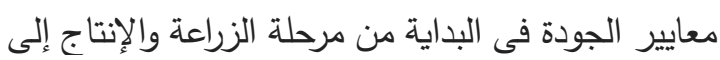

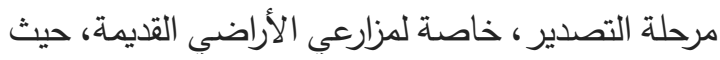

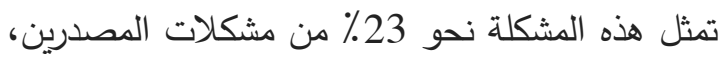

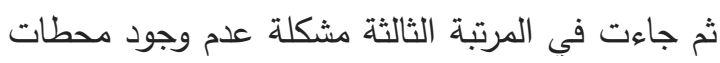
فرز وتعبئة كافية متساوية مع مشكلة ارتفاع تكاليف النقل

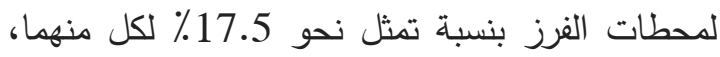
جاءت في المركز الأخير مشكلة عدم وجود مكان للتبريد والتخزين وبنسبة تقدر بنحو 16 الأير من من الآراء للمصدرين حول أهم مشاكل التسويق التي يجب مبن مواجهتها خلال

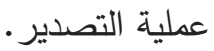

جدول 17. الأهمية النسبية لأهم مشكلات التسويق في ع عينة البحث

\begin{tabular}{|c|c|c|}
\hline الألهمية & المصدربن & المشكلة \\
\hline 26 & 30 & الميناء التصاع تكاليف النقل إلي \\
\hline 23 & 26 & بمواصفات الجودة المزارعين \\
\hline 17.5 & 20 & عدمج وجود محطات فرز \\
\hline 17.5 & 20 & محطات الفرزاع تكاليف النقل إلي \\
\hline 16 & 18 & والتخزم وجود مكان للتبريد \\
\hline
\end{tabular}

المصدر:جمعت وحسبت: من استمارة الإستبيان الخاصة بعينة البحث، 2020
25٪ من إجمالي مصالح المنتجين المصدرين ويأتي في الإي

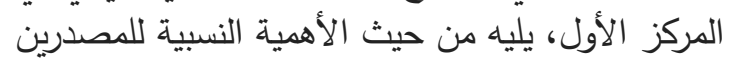
مشكلة المياه لا تصلح للري (الصرف الصن الصحي أو مياه

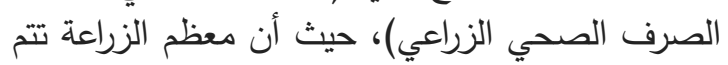

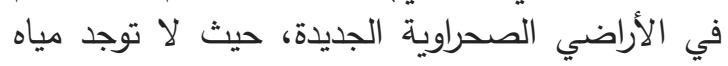

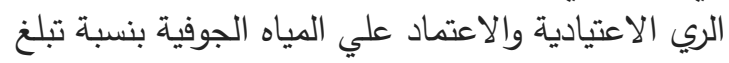
نحو 23\% من مشكلات المصدرين، ثم جاءت في المركز الثالث بنسبة تبلغ نحو 21 21 مشكلة الإنتاج في مواعيد

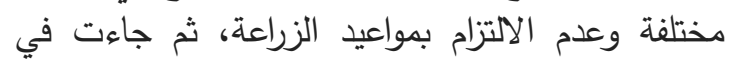

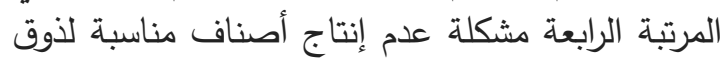

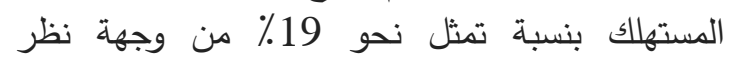
المصدرين حول أهم مشكلات الإنتاج التي تواجه عملية

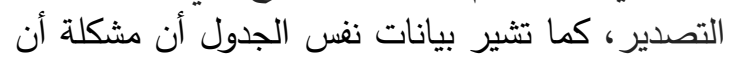

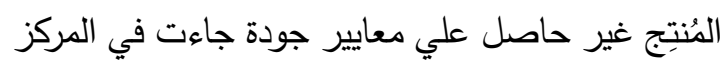

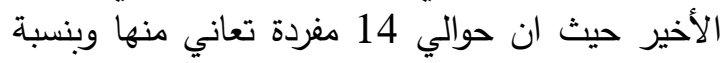
تبلغ نحو 12\% من آراء المصدرين حول أهم المشكلات الإنتاجية الي تقابلهم أثناء القيام بالعملية التصديرية.

جدول 16. الأهمية النسبية لأهم المشكلات الإنتاجية في عينة البحث

\begin{tabular}{|c|c|c|}
\hline $\begin{array}{l}\text { الأهمية } \\
\text { النسبية } \\
\text { \% }\end{array}$ & المصدرين & المشكلة \\
\hline 25 & 28 & تذبذب الإنتاج المحلي \\
\hline 23 & 26 & 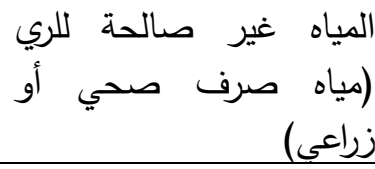 \\
\hline 21 & 24 & وعدم الإلتزام في ميعاد مختلف الزيعاد \\
\hline 19 & 22 & لذوق إنتاج أصناف مناسبة \\
\hline 12 & 14 & معايير جودة غيرتج \\
\hline
\end{tabular}

المصدر : جمعت وحسبت من استمارة الإستبيان الخاصة بعينة البحث 2020. 
لمعايير الجودة ، تليها المرتبة الخامسة والأخيرة، مشكلة غياب الشركات التى تمنح معايير الجودة، بمعدل يمثل نحو 10\% من مصالح المصدرين.

جدول 19. الأهمية النسبية لأهم المشكلات التى تواجه تطبيق الجودة فى عينة البحث

\begin{tabular}{|c|c|c|}
\hline الأهمية & المصدربن & المشكلة \\
\hline 24 & 30 & عدم وجود عمالة مدربة \\
\hline 22.5 & 28 & الرتقاع تكلفة الحصول على \\
\hline 22.5 & 28 & عدم توفر المعلومات اللازمة \\
\hline 21 & 26 & إنخفاض لمعايير الجودة والمزارع \\
\hline 10 & 12 & للمعايير وجود جهات مانحة \\
\hline
\end{tabular}

المصدر: جمعت وحسبت: من استمارة الإستيان الخاصة

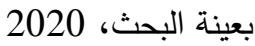

تاسعاً: أهم المقترحات لحل المشكلات في عينة البحث المقات المقات يتتاول هذا الجزء من البحث المقترحات المل المثكات في المقدمة من الشركات المصدرة في عينة البحث والتى تم من خلالها

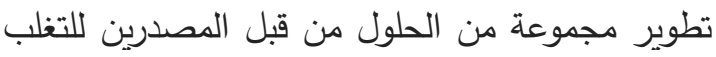
على مشكلات الإنتاج والتسويق والتمويل وتطبيق معايير

من خلال مراجعة بيانات الجدول رقم 20 تبين أن

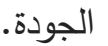

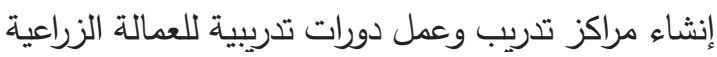

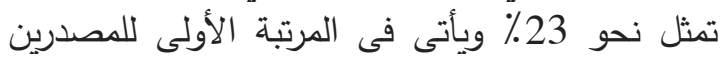

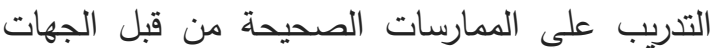
الحكومية، مثل الإرشاد الزراعى وتفعيل دور الإرشاد التياد

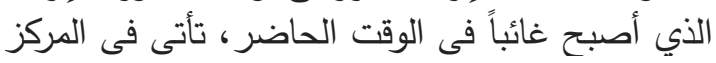

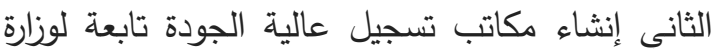

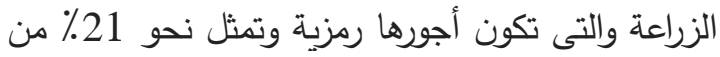

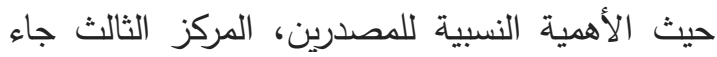

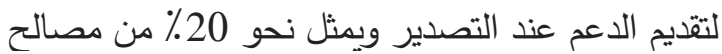

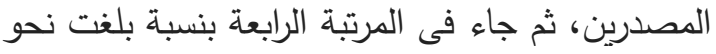

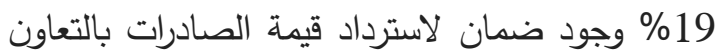
مع مكاتب التمثيل التجاري، ثم يليه المركز الخامس
3- - 3شاكل التمويل يوضح الجدول رقم 18 الأهمية النسبية لأهم

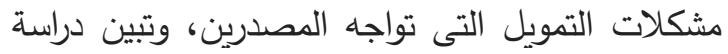

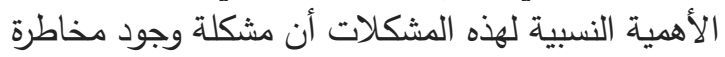

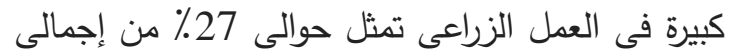
مصالح المصدرين وتأتى فى المركز الأول، تليها مشكلة التئل

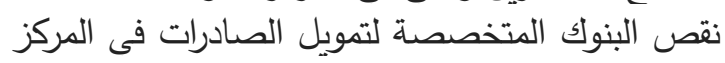
الثانى بنسبة بلغت نحو 25\%، ثم جاءت الثي في المرتبة

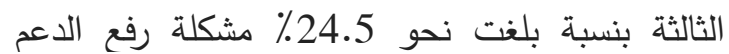
والضمانات عن محاصيل التصدير ، وتأتى في المرتبة لأنية

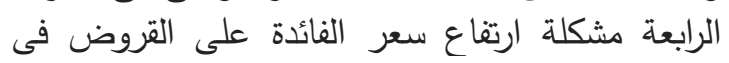
البنوك بنسبة تمثل نحو 23.5٪ من آراء المصدرين. جدول 18. الأهمية النسبية لأهم مشكلات التمويل في

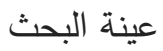

\begin{tabular}{|c|c|c|}
\hline 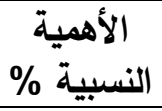 & المصدربن & المشكلة \\
\hline 27 & 28 & وجود مخاطرة كبيرة في \\
\hline 25 & 27 & 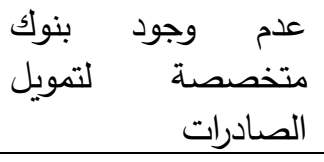 \\
\hline 24.5 & 26 & رفح الدعم والضمان عن التصديرية \\
\hline 23.5 & 25 & نسبة الفائدة العالية علي \\
\hline
\end{tabular}

4- مشكلات تطبيق معايير الجودة يوضح الجدول رقم 19 الأهمية النسبية لأهم المشكلات التى تواجه تطبيق معايير الجودة، وتبين أن الن النية

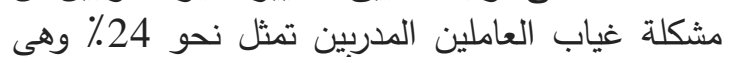

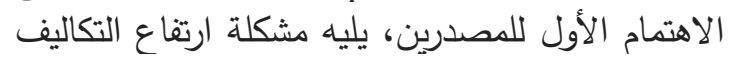

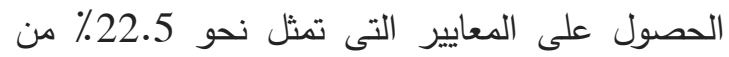
إجمالى مشاكل المصدرين، حيث جاءت التئ في المرتبة

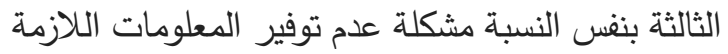

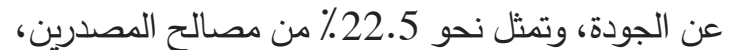

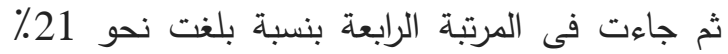
مشكلة إنخفاض المحطات والمزارع المطبقة. بالنسبة 
2-إنثاء مراكز للتدريب علي معايير الجودة في مصر

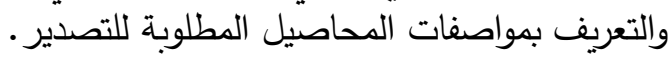

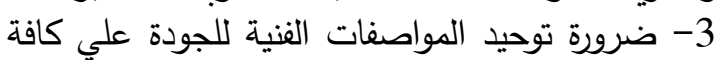
المؤسسات الداخلية والخارجية ليتم تطبيقها في مراحل الإنتاج والتصدير معاً. 4- العمل علي توفير البيانات والمعلومات الخاصة

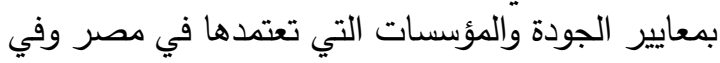
الخارج وعمل نشرات إرشادية بها.

$$
\text { المراجـع }
$$

أشرف عبد الله الفتيانى، محمد مصطفى خليفة (2021) الإرشاد الاقتصادي لصادرات بعض المضان المحاصيل الرئيسية

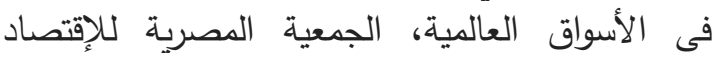

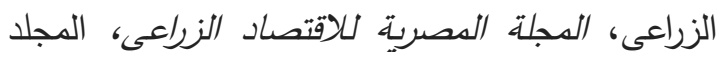
22 22

باسل فارس قنديل (2008) أثر تطبيق نظام إدارة الجودة

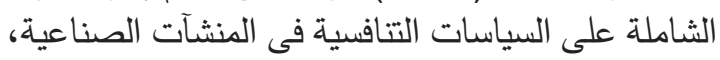

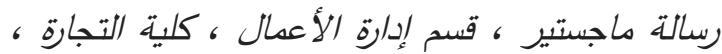
الجامعة الإسلامية، غزة، ص ص صل 147-150.

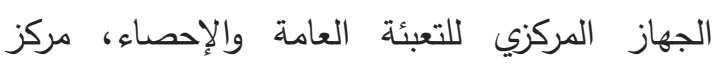
المعلومات، بيانات غير منشورة.

رئاسة الجمهورية (1992-1993) المجالس القومية المتخصصة، تقرير المجلس القومي للإنتاج والثئون الثئن

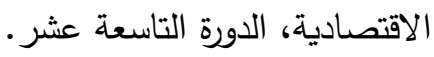

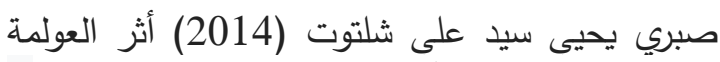

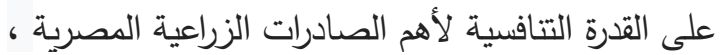

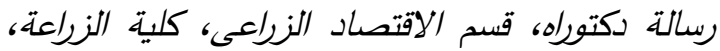

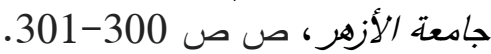

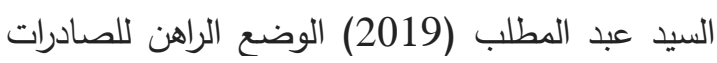

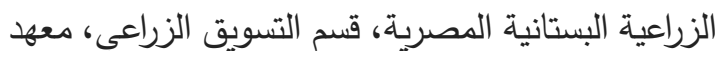

بحوث الاقتصاد الزراعي، مركز البحوث الزراعية.

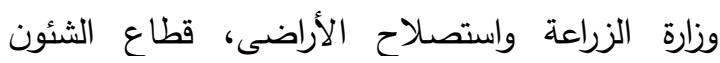

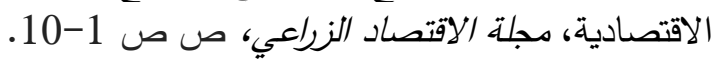

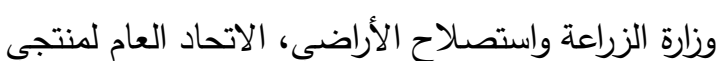
ومصدري المحاصيل البستانية.
الدعاية والإعلان بطريقة مناسبة للصادرات الزراعية

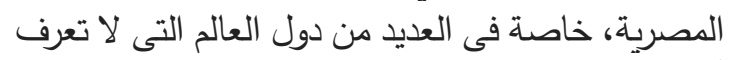

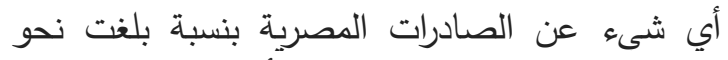

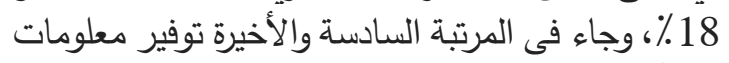

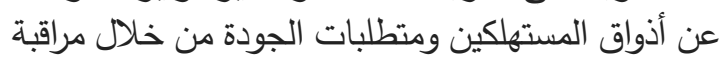

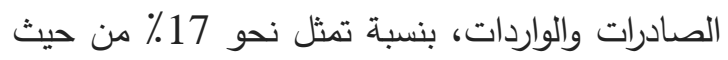

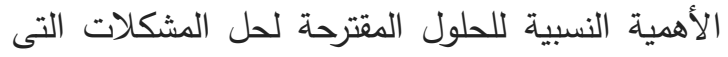

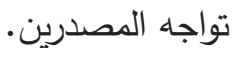

جدول 20. أهم الحلول المقترحة للمشكلات المذكورة في

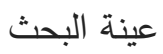

\begin{tabular}{|c|c|c|}
\hline $\begin{array}{l}\text { الأهمية } \\
\text { النسبية } \\
\text { \% }\end{array}$ & الثركات & أثر التطبيق \\
\hline 23 & 30 & الزربية إقإقامة مراكز ودورات التدريب \\
\hline 21 & 27 & إنشاءع مكاتب لتسجيل الجودة \\
\hline 20 & 26 & تقديم الدعم التصديري عند \\
\hline 19 & 25 & 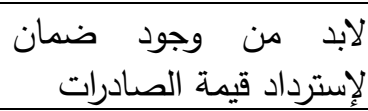 \\
\hline 18 & 24 & المصتراسب الدعاية والإعلان بمات الزراعية \\
\hline 17 & 22 & الجوديتهلكين معلومات عن أذواق \\
\hline
\end{tabular}

\section{6}

في ضوء النتائج التي توصل إليها البحث فإنه يمكن التوصية بالآتي 1- ضرورة العمل علي تطبيق معايير الجودة علي كافة المحاصيل الزراعية بداية من مرحلة الإنتاج حتي مرحلة الجئي التسويق الداخلي والخارجي. 


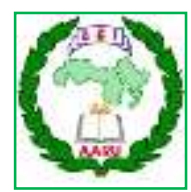

Arab Univ. J. Agric. Sci., Ain Shams Univ., Cairo, Egypt

29(1), $13-33,2021$

Website: http://ajs.journals.ekb.eg

33 DOI: 10.21608/ajs.2021.51709.1306

\title{
The Role of Quality Systems in Developing Egyptian Agricultural Exports
}

\author{
Maha ME El-Namky*, Salwa MA Abdel-Moneim, Sarhan HE \\ Agric. Economics Dept, Fac of Agric, Ain Shams Univ, P.O. Box 68, Hadayek Shoubra \\ 11241, Cairo, Egypt \\ *Corresponding author: melnamky27@gmail.com
}

Received 30 November, 2020

Accepted 8 February, 2021

\begin{abstract}
The quality of agricultural exports is one of the most important foundations on which to develop and improve these exports to global markets. Therefore, studying the effect of applying quality standards on increasing agricultural exports is one of the most important determinants for improving the system of those exports. By studying the relative importance of agricultural crops in the research sample, which is represented by potatoes and onions from vegetable crops, oranges and grapes from fruit crops, it was found that exports of potatoes and onions represent about $25 \%, 21 \%$ of total vegetable exports as an average for the period (2014-2018), while orange exports represent About 53\% of fruit exports are about $24 \%$ of the average fruit exports for the aforementioned period. By studying the effect of applying quality standards on agricultural crops from the beginning of production for export, it was found that applying these standards
\end{abstract}

leads to a reduction in agricultural losses from the crop by a rate ranging between (20-15)\%. Also, the application of quality standards leads to an increase in the costs of production and marketing of the crop, but in return, the increase in costs can be compensated for by the increase in profit through higher prices at home and abroad, in addition to benefiting from the percentage of losses that are saved. With regard to the actual effect of implementing quality, the results concluded that the rate of change before the application of quality and after the application in relation to an increase in the production of the best crop is orange by $50 \%$. The potato crop came with a $500 \%$ increase in profits, and about $355 \%$ of the return on the pound per ton.

Keywords: Quality concept, Superiority, Quality standards, Key dimensions of quality appropriateness, ISO, Reliability, Serviceability, Conformity, Competitiveness 